\title{
DERECHOS DE AUTOR Y DESARROLLO: MÁS ALLÁ DE LA ILUSORIA SOLUCIÓN PROVISTA EN EL “ANEXO” DEL “CONVENIO DE BERNA"*
}

["Copyright and Development:

Beyond the Illusory Solution Provided for in the "Berne Convention Appendix"”]

\author{
Alberto J. Cerda Silva** \\ Universidad de Chile, Santiago de Chile
}

\begin{abstract}
RESUMEN
El “Anexo" del "Convenio de Berna”, que reglamenta los derechos de autor a nivel internacional, establece normas especiales a favor de los países en desarrollo, a efectos de permitirles satisfacer su necesidad de brindar una amplia diseminación del conocimiento. Desafortunadamente, dichas normas han resultado un fracaso. Este artículo hace un análisis crítico del "Anexo" y esboza la propuesta de un nue-
\end{abstract}

\begin{abstract}
The "Berne Convention Appendix" that regulates copyright internationally, establishes special rules in favor of developing countries in order to allow them meet their need to spread knowledge. Unfortunately, said rules have proved to be a failure. This article undertakes a critical analysis of the "Apendix" and outlines the proposal for a new international vehicle
\end{abstract}

* Una versión preliminar de este artículo fue presentada en el Seminario "Theoretical Foundations of the Intellectual Property”, impartido por la Profesora Julie E. Cohen en Georgetown University Law Center, el otoño de 2011. El autor expresa su agradecimiento a la profesora Cohen por sus valiosos comentarios y sugerencias. Invaluables recomendaciones fueron también provistas por James Love, Manon Ress, Michelle Ueland, y los asistentes al Global Congress on Intellectual Property and the Public Interest (25 al 27 de agosto de 2011) y al DC-area S.J.D. Paper Roundtable (7 de diciembre de 2011), ambos eventos organizados por American University Washington College of Law. Los errores son completa y exclusiva responsabilidad del autor.

** Alberto J. Cerda Silva, LL.M in International Legal Studies, Georgetown University; Magíster en Derecho Público, Universidad de Chile. Profesor Asistente de Derecho Informático de la Universidad de Chile. Becario de la Comisión Fulbright y de la Comisión Nacional de Ciencia y Tecnología (CONICYT) prosiguiendo estudios doctorales en Georgetown University Law Center. Correo electrónico: acerda@uchile.cl. 
vo instrumento internacional que provea flexibilidades apropiadas para satisfacer necesidades de desarrollo.

Palabras clave

Derechos de autor - Desarrollo Licencias obligatorias - Convenio de Berna. that provides proper flexibilities to meet the development needs.

$$
\begin{gathered}
\text { KeYwords } \\
\text { Copyright }- \text { Development - Obliga- } \\
\text { tory Licenses - Berne Convention. }
\end{gathered}
$$

Recibido el 5 de enero y ACEPTADo el 29 de marzo de 2012.

\section{INTRODUCCIÓN}

El estándar de protección para los derechos de autor promovido por el Convenio para la protección de las obras literarias y artisticas (= "Convenio de Berna”) es problemático para los países en desarrollo, pues éstos enfrentan necesidades que requieren una amplia diseminación de obras a efectos de enseñanza, estudios, e investigación. Precisamente por ello, a fin de promover el acceso a las obras, el mencionado Convenio adoptó ciertas flexibilidades especialmente diseñadas para satisfacer las necesidades de aquellos países. A través del "Acta de París" de 1971, el "Convenio de Berna” incluyó un “Anexo" que permite a los países en desarrollo emitir licencias obligatorias para la traducción o reproducción de obras extranjeras a un idioma de uso general en su territorio.

El creciente número de países en desarrollo que ha venido a ser parte del "Convenio de Berna" puede sugerir que el mecanismo provisto por el “Anexo" satisfizo sus necesidades, pero no es así. Al revisar la normativa interna sobre derechos de autor de aquellos países queda en claro la inutilidad de las disposiciones del "Anexo", lo que ha movido a tales países a adoptar soluciones idiosincráticas que varían de un país a otro. Además, el mencionado instrumento no provee una solución para otras necesidades de desarrollo, tales como aquéllas de minorías lingüísticas y culturales, y es discutible si él aplica a entornos en línea (e.g., a Internet). Estas limitaciones deberían ser resueltas en un nuevo instrumento que proveyese una solución real para las necesidades de desarrollo. Este artículo formula una propuesta con los asuntos que deberían ser incluidos en tal nuevo instrumento.

La primera sección de este artículo provee antecedentes acerca de las necesidades de los países en desarrollo y de cómo el "Anexo" del "Convenio de Berna” trató de satisfacerlas. Enseguida, la segunda sección analiza las principales limitaciones del mecanismo de licencias obligatorias adoptado por el "Anexo". El solo hecho de que éste no satisfaga sus propios objetivos sería suficiente para motivar la creación de un nuevo instrumento; la sección 
tercera, sin embargo, provee dos argumentos adicionales a favor de la adopción de un nuevo instrumento con flexibilidades para satisfacer necesidades de desarrollo, uno basado en una lógica de bienestar general y otro basado en los beneficios económicos para autores y titulares de derechos. Finalmente, la sección cuarta de este artículo esboza los asuntos que deberían incluirse en una nueva solución que satisfaga las necesidades de desarrollo.

\section{El “Anexo" Del “Convenio de Berna”}

En 1886, los países europeos convinieron un estándar mínimo de protección de los derechos de autor a través de la suscripción en Berna del Convenio para la protección de las obras literarias y artísticas ${ }^{1}$. A pesar de que otros países también aparecían como partes del Convenio, ello era bajo su status colonial; los países realmente interesados eran Alemania, España, Francia, Italia y el Reino Unido. Como resultado de ello, ese Convenio reflejó los intereses de esos países por alcanzar una adecuada protección, especialmente respecto de su potencial mercado colonial. Desde entonces, sucesivas revisiones del Convenio tuvieron lugar, siendo quizá la de Berlín la más relevante ${ }^{2}$, porque ella dispensó de cumplir con formalidades al adoptar un sistema de protección automática y, al mismo tiempo, estableció un plazo mínimo de protección - la vida del autor más cincuenta años post mortem, el cual se transformó en obligatorio en el "Acta de Bruselas" de 1948 .

Los recientemente independizados países de las Américas también adoptaron su propio sistema de protección para los derechos autorales. Desde 1889, a través del "Tratado de Montevideo" y sus sucesivas actualizaciones 4 , los países americanos se proveyeron a sí mismos con un sistema de protección más flexible que se ajustaba mejor a sus necesidades. El sistema interamericano dejaba la determinación del plazo de protección al derecho interno de cada país y exigía el registro de las obras para su protección ${ }^{5}$, dejando aquellas obras que no cumplían con las formalidades en el dominio público. Además,

${ }^{1}$ Convenio para la protección de las obras literarias y artísticas (Berna), "Acta de París” del 24 julio de 1971 y enmendado el 28 de septiembre de 1979. En este artículo todas las referencias al "Convenio de Berna" lo son al "Acta de París" de 1971 enmendada en 1979, salvo que se consigne expresamente lo contrario.

${ }^{2}$ Convenio para la protección de las obras literarias y artísticas (Berna), "Acta de Berlín" de 13 de noviembre de 1908.

${ }^{3}$ Convenio para la protección de las obras literarias y artísticas (Berna), "Acta de Bruselas" de 26 de junio de 1948.

${ }^{4}$ Tratado sobre propiedad literaria y artística, firmado en Montevideo el 11 de enero de 1889.

${ }^{5} \mathrm{La}$ abolición de formalidades para la obtención de protección de una obra tiene lugar recién en 1946. Véase el artículo 9 de la Convención interamericana sobre el dere- 
como política general, los países americanos rechazaron la adhesión al sistema interamericano de los países europeos, impidiendo la protección de las obras de estos últimos en sus antiguas colonias ${ }^{6}$. Una protección más relajada y el rechazo a la adhesión europea hacen evidente los intereses divergentes en torno a la impresión de obras ${ }^{7}$; los países americanos rechazaban la hegemonía europea y pretextaban obstáculos legales para adoptar el modelo europeo de protección autoral, pero, por sobre todo, tenían una clara convicción de que este modelo les era inconveniente como países importadores de cultura ${ }^{8}$.

Después de la Segunda Guerra Mundial, la progresiva descolonización de África y Asia disminuyó la eficacia del “Convenio de Berna”. La denominada "cláusula colonial" incluida en el Convenio para proveer continuidad a la protección de las obras en territorios descolonizados no era suficiente, porque ésta aún requería que los nuevos países ratificasen o se retractasen de él'. Sin embargo, los altos estándares del "Convenio de Berna” no satisfacían las expectativas de los nuevos países en desarrollo, desincentivándoles a ser partes del Convenio.

Los países en desarrollo tenían la necesidad, y aún la tienen, de acceder a una amplia diseminación del conocimiento lo cual es obstaculizado por la escasez artificial creada por las leyes sobre derechos autorales. Los altos precios de las obras en otros idiomas publicados en el extranjero impiden el desarrollo de políticas públicas que supongan un uso extensivo de obras protegidas por el derecho de autor para el desarrollo educacional, cultural, y técnico de aquellos países y su población. Las compras públicas y las licencias voluntarias no satisfacían dicha necesidad, dado su desproporcionado alto costo comparado con los limitados recursos económicos de los países en desarrollo. Para llegar a ser partes del "Convenio de Berna”, los países en desarrollo necesitaban de flexibilidades apropiadas que les permitiesen satisfacer sus necesidades ${ }^{10}$.

cho de autor en obras literarias, cientificas y artísticas, adoptada en Washington D.C., el 22 de junio de 1946.

${ }^{6}$ Lipszyc - Villalba - Uchtenhagen, La protección de los derechos de autor en el Sistema Interamericano (Bogotá, Universidad Externado de Colombia y Dirección Nacional de Derechos de Autor, 1998), pp. 78-80.

${ }^{7}$ Ibíd.

${ }^{8}$ Ibíd., p. 20; Plazas, Arcadio, Estudios sobre derecho de autor: Reforma legal colombiana (Bogotá, Temis, 1984), pp. 102-103.

${ }^{9}$ Artículo 31 del "Convenio de Berna”.

${ }^{10}$ Olian Jr., Irwin A., International Copyrights and the Need of Developing Countries: The Awakening at Stockholm and Paris, en Cornell International Law Journal, 7 (1974) 2, pp. 81-112; Drahos, Peter - Braithwaite, John, Information Feudalism: Who Owns the Knowledge Economy? (Londres, Earthscan Publications, 2002), pp. 7479. 
El "Convenio de Berna" ofrece algunas flexibilidades, pero ellas son insuficientes para satisfacer las necesidades de países en desarrollo. El Convenio permite acceder a las obras protegidas por los derechos de autor a través de excepciones o limitaciones. Éstos son usos autorizados por ley y que no requieren ni del consentimiento ni de pago alguno al titular de los derechos autorales; sin embargo, estos usos están sujetos a la denominada “" prueba de los tres pasos" ", que circunscribe las excepciones a determinados casos especiales, que no atentan contra la explotación normal de la obra ni cause un perjuicio injustificado a los intereses legítimos del autor ${ }^{11}$. Esta prueba reduce las posibilidades para hacer un uso extensivo de las obras por los países en desarrollo, porque, aún si la motivación política es más altruista y urgente que proveer entretención en pequeños boliches y restaurantes ${ }^{12}$, la prueba no permite un uso masivo de obras protegidas para efectos educacionales.

Otra flexibilidad prevista para todos los países en el "Convenio de Berna" es el llamado "régimen de diez años", una norma que permite la extinción anticipada de la protección de algunas obras. Un país que accede al Convenio puede sustituir el derecho exclusivo de traducción por la extinción de los derechos autorales si la obra no está disponible en un idioma de general uso en el territorio del mencionado país dentro de los diez años siguientes a su primera publicación ${ }^{13}$. En consecuencia, la obra en cuestión ingresa al dominio público en dicho país, permitiendo su explotación por cualquiera, lo cual podría facilitar la satisfacción de las necesidades de países en desarrollo al permitir un uso masivo de las obras a efectos educacionales. Sin embargo, esta flexibilidad no es satisfactoria por diferentes razones. Primero, ella está diseñada para atraer países a acceder al "Convenio de Berna", no para satisfacer las necesidades de países en desarrollo, mediante la formulación de una reserva ${ }^{14}$. Segundo, porque los restantes países pueden adoptar represalias en contra de los autores de aquellos países que han implementado

${ }^{11}$ Artículo 9 (2) del "Convenio de Berna”. Véase también artículo 13 del Acuerdo sobre los aspectos de los derechos de propiedad intelectual relacionados con el Comercio (ADPIC), de 15 de abril de 1994, "Convenio de Berna Marrakesh", que establece la Organización Mundial de Comercio, "Anexo" 1C, 1869 U.N.T.S. 299, el cual adopta similar test, pero extiende su ámbito más allá de la reproducción y refiere a que no se cause un perjuicio injustificado a los intereses legítimos del titular de los derechos.

${ }^{12}$ Véase: Report of the Panel on United States, Section 110(5) of the US Copyright Act, document WT/DS160/R (June 15, 2000), en que el panel arbitral juzga la consistencia de la excepción prevista en la sección 110 (5) (B) de la Copyright Act de los Estados Unidos con la "prueba de los tres pasos", en donde se resolvió que la primera infringe esta última.

${ }^{13}$ Véanse los artículo 30 (2) (b) del "Convenio de Berna”; artículo V del "Anexo" del "Convenio de Berna".

${ }^{14}$ Véase: World Intellectual Property Organization, Guide to the Berne Convention 
este mecanismo, lo cual es permitido por el Convenio ${ }^{15}$. Tercero, porque el régimen de diez años es incompatible con las disposiciones especiales a favor de países en desarrollo establecidas por el "Anexo" del "Convenio de Berna"16. Y, por último, porque el régimen de diez años retrasa el acceso a las obras por un período significativo de tiempo. Esto último puede no ser un serio problema en ciencias sociales y filosofía, pero es inaceptable en otras áreas del conocimiento, tales como tecnología y ciencias de la computación, epidemiología, oncología, y ciencias de la salud en general. Como resultado de dichas limitaciones, los países que acceden al "Convenio de Berna” rara vez han hecho uso de la reserva y, por consiguiente, el régimen de diez años ha devenido en inútil ${ }^{17}$.

Para superar la brecha entre las necesidades de los países en desarrollo y la protección promovida por los países europeos, en 1952, bajo los auspicios de la Organización de las Naciones Unidas para la Educación, la Ciencia y la Cultura (UNESCO), se adoptó la Convención universal de derechos de autor $^{18}$. Ella proveyó un "puente" hacia los elevados estándares del "Convenio de Berna”, mediante la adopción de algunas flexibilidades, incluidas excepciones, limitaciones, y un período de protección más corto ${ }^{19}$; pero este era un puente en una sola dirección, pues no permitía ir desde el "Convenio de Berna” hacia la Convención universal ${ }^{20}$. Esta solución resultaba insatisfactoria, porque no alentaba la adhesión al "Convenio de Berna" por los países en desarrollo y, al mismo tiempo, no evitaba la retractación del Convenio por los pocos países en desarrollo que ya eran miembros de él. En consecuencia, encontrar una solución diferente resultaba imperativo.

Un primer intento por insertar ciertas flexibilidades en el "Convenio de

for the Protection of Literary and Artistic Works (Paris Act, 1971) (Ginebra, WIPO, 1978), p. 172.

${ }^{15}$ Véase el artículo 30 (2) (b) del "Convenio de Berna".

${ }^{16}$ Véase el artículo V del "Anexo" del "Convenio de Berna".

${ }^{17}$ Desde la adopción del "Acta de Paris" de 1971, del "Convenio de Berna” solo un puñado de países han hecho reserva del derecho a extinguir la protección de las obras que carecen de traducción: Eslovenia y algunos de los países que sucedieron a la antigua Yugoslavia (Bosnia y Herzegovina, Croacia, y Serbia). Véase: World Intellectual Property Organization, Berne Convention Contracting Parties and Notifications, disponible en http://www.wipo.int/treaties/en/ip/berne/index.html (última visita: 26 de noviembre de 2011).

${ }^{18}$ Convención universal sobre derecho de autor, Ginebra, 6 de septiembre de 1952.

${ }^{19}$ Véase: Lipszyc, Delia, Copyright and Neighbouring Rights, (Paris, UNESCO Publishing, 1999), pp. 604-605, 751; ANTEQUERA, Ricardo, El nuevo derecho de autor en Venezuela (Caracas, Autoralex, 1994), p. 572.

${ }^{20}$ Declaración relativa al artículo XVII de la Convención Universal sobre Derecho de Autor, Ginebra, 6 de septiembre de 1952. 
Berna" tuvo lugar en el "Acta de Estocolmo" de $1967^{21}$, la cual esencialmente estableció un protocolo con flexibilidades para países en desarrollo basadas en la expiración de los derechos de autor en obras extranjeras carentes de traducción en dichos países ${ }^{22}$. La falta de ratificación del protocolo particularmente por los países desarrollados, sin embargo, hizo rápidamente evidente su inutilidad $^{23}$. Un segundo intento concluyó con la modificación simultánea de la Convención universal de derechos de autor y la adopción de un "Anexo" en el "Convenio de Berna" a través del "Acta de París" de 197124. Desde entonces, ambos instrumentos internacionales suministran un mecanismo convergente que provee flexibilidades a los países en desarrollo, los cuales pueden emitir licencias obligatorias para la traducción o reproducción de obras protegidas por los derechos de autor, tal como se explica a continuación ${ }^{25}$.

El sistema de licencias obligatorias establecido en el "Anexo" está diseñado específicamente para los países en desarrollo. Aquellos países interesados en aplicar el sistema necesitan calificar como "en desarrollo" de acuerdo a las prácticas de Naciones Unidas, y habilitarse a sí mismos mediante una notificación periódica al director general de la $\mathrm{OMPI}^{26}$. Adicionalmente, incluso si las disposiciones del "Anexo" fuesen auto-ejecutables ${ }^{27}$, los países necesitan implementar varias de sus disposiciones en su derecho interno, tal como las reglas que determinan la autoridad competente para emitir las licencias, los procedimientos a aplicar, y las medidas de resguardo en favor de los titulares de derechos, entre otras. En consecuencia, para ser completamente operativo, el mecanismo adoptado por el "Anexo" requiere notificar

${ }^{21}$ Convenio para la protección de las obras literarias y artísticas (Berna), "Acta de Estocolmo" del 14 de julio de 1967.

${ }^{22}$ Véase: Ricketson, Sam, The Berne Convention for the Protection of Literary and Artistic Works: 1886-1986 (Londres, Kluwer, 1987), pp. 590-630; Ricketson, Sam - Ginsburg, Jane C., International Copyright and Neighbouring Rights: The Berne Convention and Beyond (2a edición, Oxford University Press, 2006), pp. 881-924; Mouchet, Carlos, El derecho de autor internacional en una encrucijada (Buenos Aires, Sociedad de Autores y Compositores de Música, 1969); Ndiaye, Ndéné, The Berne Convention and Developing Countries, en Columbia-VLA Jounal of Law \& the Arts, 11 (1986), pp. 47-56.

${ }^{23}$ Drahos - Braithwaite, cit. (n. 10), p. 77.

${ }^{24}$ Ulmer, Eugen, The Revisions of the Copyright Conventions, en International Review of Intellectual Property and Competition Law, 345 (1971) 2, p. 347

${ }^{25}$ En contra, Olian, Jr, Irwin A., cit. (n. 10), el cual sostiene que, aun cuando el "Acta de París" del "Convenio de Berna” introdujo un régimen de licencias obligatorias en favor de los países en desarrollo, su verdadera meta ha sido uniformar los sistemas de protección ofrecidos por el "Convenio de Berna" y la Convención universal sobre derechos de autor.

${ }^{26}$ Véase el artículo I (1) y (2) del "Anexo" del "Convenio de Berna".

${ }^{27}$ Véase el artículo 36 (1) del "Convenio de Berna”. 
al director general de la OMPI e implementar sus disposiciones en el derecho interno del país en cuestión ${ }^{28}$.

La autoridad competente de los países en desarrollo pueden emitir licencias no-exclusivas y no-transferibles para $^{29}: i$ ) traducir a un idioma de general uso en el país y publicar la traducción en forma impresa o en cualquier otra forma análoga de reproducción para fines de enseñanza, estudio, e investigación ${ }^{30} ; \mathrm{y} i$ ) reproducir una obra publicada en forma impresa o en cualquier otra forma análoga de reproducción para su uso en conexión con actividades de instrucción sistemática ${ }^{31}$. Para traducción, existe un período de espera cuya extensión varía de acuerdo a la lengua de orígen de la obra; para reproducción, en cambio, el período de espera depende de si la obra tiene un carácter esencialmente técnico o no.

El "Anexo" adopta varias medidas de resguardo a favor del titular de los derechos de autor. Además de los requisitos antes mencionados, el potencial licenciatario, quien debe ser nacional del país que emite la licencia, necesita localizar y tratar de obtener una licencia voluntaria del titular de los derechos, e indicar en todas las copias que la obra está disponible bajo las disposiciones del "Anexo". Apropiadas disposiciones deben garantizar una traducción correcta de la obra, una reproducción exacta de la edición, y el pago de una remuneración equitativa, la cual debe ser ajustada a la escala de cánones que normalmente se abonen en los casos de licencias libremente negociadas entre los interesados en los dos países de que se trate. Salvo muy limitadas circunstancias, la exportación de la obra está prohibida. Medidas de resguardo adicionales son establecidas en caso de que la obra llegue a estar disponible a un precio razonable a través del titular de los derechos, mediante el cese de la licencia obligatoria, si bien permitiendo el agotamiento de las copias en stock, así como para el caso de que el país que emitió la licencia deje de calificar como uno en desarrollo.

El "Anexo" prohíbe la represalia por parte de países partes del "Convenio de Berna" en contra de aquellos países que expiden licencias obligatorias ${ }^{32}$. Esta garantía fue acordada unánimemente durante la Conferencia Diplo-

${ }^{28}$ Plazas, Arcadio, cit. (n. 8), p. 166.

${ }^{29} \mathrm{El}$ "Anexo" del "Convenio de Berna” establece, en adición, una licencia obligatoria para radiodifusión en países en desarrollo, sobre la base de que tales países podrían aprovechar tal difusión a efectos de proveer educación. Sin embargo, esta licencia no es analizada en este artículo, el cual se concentra en el análisis de las licencias obligatorias para traducción y reproducción de material en forma impreso u otras formas análogas de reproducción.

${ }^{30}$ Artículo II del "Anexo" del "Convenio de Berna”.

${ }^{31}$ Artículo III del "Anexo" del "Convenio de Berna".

${ }^{32}$ Artículo I (6) (a) del "Anexo" del "Convenio de Berna”. Véase: Report of the General Repporteur of the Universal Copyright Convention, párrafos 58-59, en UNESCO, 
mática en que el "Anexo" fue adoptado a efectos de evitar que los países limitasen sus obligaciones respecto de otros países a fin de evitar que éstos emitieran dichas licencias ${ }^{33}$. En consecuencia, a diferencia de la cláusula sobre régimen de diez años, los titulares de derechos de aquellos países de origen que han expedido licencias obligatorias no deberían temer una menor protección por parte de los países cuyos autores han sido afectados por las licencias emitidas ${ }^{34}$.

En síntesis, el "Anexo" del "Convenio de Berna" intenta proveer una solución para los países en desarrollo permitiéndoles expedir licencias obligatorias no exclusivas y no transferibles para la traducción y la reproducción de obras publicadas en forma impresa u otras formas análogas de reproducción, a efectos de satisfacer sus necesidades educacionales y de investigación, bajo el pago de una remuneración equitativa a los titulares de los derechos de autor. Esto podría permitir a los países en desarrollo disponer de una amplia diseminación del conocimiento para enseñanza, estudio, e investigación, tal como a través de textos de estudio y manuales, entre otros ${ }^{35}$.

\section{LIMITACIONES DEL MECANISMO DEL “ANEXo"}

Después de algunos años de vigencia, el "Anexo" pareció haber cumplido su propósito político, al tornar el "Convenio de Berna" en un instrumento más atractivo para los países en desarrollo, los que han adherido a él con la promesa de disfrutar de los beneficios de disposiciones especialmente diseñadas para ellos. En 1970, el año antes de la adopción del "Anexo", el "Convenio de Berna" totalizaba 58 países parte; de ellos, 21 eran parte de la Organización para la Cooperación y el Desarrollo Económicos (OCDE), que esencialmente aglutina las economías más desarrolladas del mundo; de hecho, todos los países miembros de la OCDE eran miembros del Convenio, excepto los Estados Unidos. También 28 países europeos eran parte del Convenio. Impresionantemente, después de la adopción del "Anexo", tal como muestra la figura 1 , el número de países parte se ha incrementado continuamente a través de los años y de los continentes, llegando hoy a un total de 164 países $^{36}$. Este éxito podría sugerir que la solución provista por el

Records of the Conference for Revision of the Universal Copyright Convention (Paris, UNESCO, 1973), pp. 55-93.

${ }^{33}$ Ulmer, Eugen, cit. (n. 24), p. 356.

${ }^{34}$ Véase: General Report of Paris Conference, en World Intellectual Property Organization, Records of the Diplomatic Conference for the Revision of the Berne Convention (Paris, July 5 to 24, 1971) (Ginebra, WIPO, 1974), párrafo 28.

${ }^{35}$ World Intellectual Property Organization, cit. (n. 14), p. 153.

${ }^{36}$ World Intellectual Property Organization, Berne Convention Contracting 
"Anexo" del "Convenio de Berna" funciona; sin embargo, tal como se explica a continuación, tal conclusión es errada.

\section{FigurA 1:}

Países partes del "Convenio de Berna” y de la Organización para la Cooperación y el Desarrollo Económicos, 1970-2010.

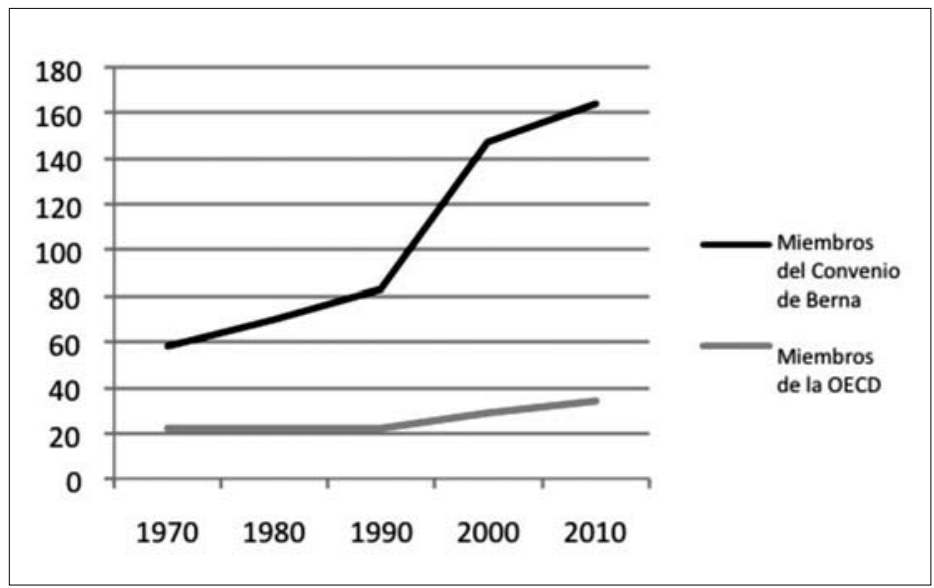

Funnte: Sitios web de la OMPI y de la OCDE, 2011.

Los países en desarrollo se han hecho parte del "Convenio de Berna" a raíz del Acuerdo de la Organización Mundial de Comercio (OMC) sobre los Aspectos de los Derechos de Propiedad Intelectual relacionados con el Comercio (“Acuerdo sobre los ADPIC”). Hasta 1990, sólo 83 países eran parte del Convenio, pero su número se duplicó a partir de entonces, porque las negociaciones de lo que vendría a ser la OMC requerían a sus miembros adoptar los estándares del "Convenio de Berma”. En consecuencia, un significativo número de países parecen haber accedido al Convenio por razones diferentes a estar de acuerdo con los estándares de ella, sino que presumiblemente para obtener acceso a mercado para sus productos agrícolas ${ }^{37}$. Pero, cualquiera sea la razón para explicar su adhesión al Convenio, al analizar la real aplicación y desafíos de las disposiciones establecidas por el "Anexo" se torna evidente que éste no creó un mecanismo que los países en desarrollo pueden usar para abordar los problemas asociados con su estadio de desarrollo.

Parties, disponible en http://www.wipo.int/treaties/es/ShowResults.jsp?country_ $\mathrm{id}=$ ALL\&start_year=ANY\&end_year $=$ ANY\&search_what $=$ C\&treaty_id $=15 \quad$ (fecha de consulta: 15 de mayo de 2011).

${ }^{37}$ Véase Yu, Peter, TRIPS and Its Discontents, en Marquette Intellectual Property Law Review, 10 (2006) pp. 369-410. 
El "Anexo" del "Convenio de Berna" no funciona porque él no satisface las necesidades de los países en desarrollo. En cambio, este parece un obsoleto, inapropiado, burocrático, y extremadamente limitado intento por proveer una válvula de aire a los países en desarrollo. Las siguientes páginas describen y analizan algunos de los problemas de las disposiciones del "Anexo" en orden a ilustrar una propuesta de enmienda, la que también se discute más adelante.

\section{El "Anexo" no sirve a los países en desarrollo.}

La suposición de que los países en desarrollo ya tienen una solución contrasta con el (des)uso real de las disposiciones del "Anexo" y la legislación interna de los países en materia de derechos de autor. En primer término, sólo un puñado de países se han habilitado a sí mismos notificando al director general de la OMPI. En segundo término, varios países que han introducido mecanismos análogos en su legislación interna no han notificado al director general de la OMPI, precisamente por la inutilidad del mecanismo. En cambio, los países han adoptado soluciones idiosincráticas en su legislación interna, a efectos de mitigar las limitaciones del mecanismo provisto en el "Anexo" del "Convenio de Berna".

Un pequeño número de países en desarrollo se han habilitado a sí mismos para hacer uso de las flexibilidades previstas en el "Anexo". Como ya se ha mencionado, estos países deben habilitarse a través de una notificación periódica al director general de la OMPI, lo que les permitiría emitir licencias obligatorias de acuerdo a las disposiciones del "Anexo"38. De hecho, el 2011 el registro en línea de las notificaciones efectuadas a la OMPI consigna que sólo 15 de los 164 países partes del "Convenio de Berna" se habían habilitado para emitir tales licencias ${ }^{39}$. Estos son principalmente países de Asia y el Medio Oriente ${ }^{40}$, más un país de África y otro de Latinoamérica ${ }^{41}$, la mayor

${ }^{38}$ Artículo II (1) y (2) del “Anexo” del Convenio de Berna.

${ }^{39}$ Véase: World Intellectual Property Organization, Notifications on the Berne Convention, disponible en http://www.wipo.int/treaties/en/ShowResults. jsp?lang=en\&search_what $=$ N\&treaty_id=15 (fecha de consulta: 15 de mayo de 2011).

${ }^{40}$ NabHan, Victor, WIPO Study on Limitations and Exceptions for Copyright for Educational Purposes in the Arab Countries, Documento OMPI, SCCR/19/6 Oct. 7, 2009 , pp. 56-57, quien identifica varios países árabes que han implementado un sistema de licencias obligatorias como el previsto en el "Anexo" del "Convenio de Berna", no obstante lo cual dichas licencias son inexistentes, transformando los textos de la ley en "letra muerta".

${ }^{41}$ Los países actualmente habilitados son: Bangladesh, Cuba, Emiratos Árabes Unidos, Filipinas, Jordania, Mongolia, Omán, Samoa, Siria, Sri Lanka, Sudan, Tailandia, Uzbekistan, Vietnam, y Yemen. 
parte de ellos recién llegados al foro internacional de los derechos de autor, los que adhirieron al "Convenio de Berna" en el contexto de los "Acuerdos sobre los ADPIC” e intentaron tomar ventaja de las flexibilidades provistas en el "Anexo".

Sin embargo, ser un país en desarrollo habilitado no hace el mecanismo funcional en sí mismo, todavía es necesario implementar apropiadamente el mismo en el derecho interno del país en cuestión. Varios países habilitados no han implementado aún ninguna licencia obligatoria para la traducción y reproducción en su derecho interno y apenas si tienen algunas excepciones y limitaciones; este es el caso de Mongolia ${ }^{42}$, Omán $^{43}$, Filipinas ${ }^{44}$, Samoa ${ }^{45}$, Sri Lanka ${ }^{46}$, Uzbekistan ${ }^{47}$ y Yemen ${ }^{48}$. Otros países habilitados, en adición a excepciones, han implementado un mecanismo de licencia obligatoria que difiere significativamente de aquél permitido por el “Anexo": Emiratos Ârabes Unidos, tiene una licencia obligatoria más flexible ${ }^{49}$; $\operatorname{Sudan}^{50}$ y $\operatorname{Siria}^{51}$ tienen una licencia obligatoria general para permitir el uso de obras protegidas por razones de interés público; Cuba tiene un sistema similar, pero sin tarifa a favor del titular de los derechos de autor ${ }^{52}$; Vietnam también tiene un sistema

\footnotetext{
${ }^{42}$ Artículo 24, Law of Mongolia on Copyright and Related Rights, January 19, 2006 (Mongolia).

${ }^{43}$ Artículo 20, Royal Decree No 65/2008 Promulgating the Law on Copyright and Related Rights (Omán).

${ }^{44}$ Secciones 176.1, 184, y 185 Intellectual Property Code of the Philippines (Republic Act No 8293) of June 6, 1997 (Filipinas). Véase: AmAdor, Vicente, Intellectual Property Fundamentals (Quezon City - Filipinas, C\&E Publishing, 2007), pp. 398399; Jimenez, Jacinto D., Intellectual Property Law in Philippines (La Haya, Kluwer International, 2007), pp. 43-48; AQUINo, Ranhilio Callangan, Intellectual Property Law: Comments and Annotations (Quezon City, Filipinas, Central Books, 2006), p. 109. Véase la sección 237 de la Intellectual Property Code of the Philippines (Republic Act No 8293) of June 6, 1997 (Filipinas), que establece que las Filipinas se habilitará para hacer uso de las provisiones establecidas en beneficio de los países en desarrollo.

${ }^{45}$ Véanse los artículos 8-10 de la Copyright Act 1998, Consolidated Acts of Samoa 2008 (Samoa). Véase también: Farran, Sue, South Pacific Intellectual Property Law (La Haya, Kluwer International, 2009), pp. 36-38.

${ }^{46}$ Véase: Intellectual Property Act, № 36 of 2003 (Sri Lanka). Véase también KARUnaratna, D.M., Introduction to the Law of Copyright and Related Rights in Sri Lanka (Sarvodaya Vishva Lekha Publication, 2006), pp. 76-90.

${ }^{47}$ Véase el artículo 26 Law of the Republic of Uzbekistan on Copyright and Related Rights 2006 (Uzbekistan).

${ }^{48}$ Véase: artículo 38 Intellectual Property Rights Law No 19 of 1994 (Yemen).

${ }^{49}$ Artículo 21 Federal Law No 7 of the Year 2002 Concerning Copyrights and Neighboring Rights (Emiratos Árabes Unidos).

${ }^{50} \$ 14$ y 20 Copyright and Neighboring Rights Protection Act 1996 (Sudan).

${ }^{51}$ \$\$ 21 y 37 Law No 12/2001 Copyright Law of Syria (Siria).

${ }^{52}$ Artículo 37 Ley No 14 del Derecho de Autor de 1977 (Cuba).
} 
parecido, pero no hace mención alguna a un pago a favor del titular de los derechos ${ }^{53}$. Jordania tiene una licencia obligatoria basada en razones de interés público, pero limitada a la publicación y republicación, y reconociendo derecho a justa compensación ${ }^{54}$, y además una licencia como la prevista en el Anexo $0^{55}$. Este último mecanismo ha sido implementado también en Bangladesh $^{56}$ y Tailandia ${ }^{57}$. En conclusión, un sistema de licencias obligatorias de acuerdo al "Anexo" ha sido implementado en solamente tres países en desarrollo debidamente habilitados: Bangladesh, Jordania, y Tailandia.

El "Anexo" del "Convenio de Berna" no ha tenido éxito entre los países en desarrollo habilitados, ya que de los quince países que han notificado al director general de la OMPI su interés en usar el mecanismo sólo tres han implementado éste en su derecho interno. Estudios adicionales son necesarios para establecer si estos pocos países efectivamente han usado el mecanismo. Sin embargo, es posible sostener que los países en desarrollo han sido simplemente negligentes en renovar su notificación a la OMPI, que ellos han implementado el mecanismo en su derecho interno, y que disfrutan de los beneficios del "Anexo". Desafortunadamente, ese no es el caso. Una revisión de la normativa interna sobre derecho de autor de varios países en desarrollo en África y Latinoamérica muestra que ellos no son beneficiarios encubiertos de la falsa generosidad de las disposiciones diseñadas para ellos en el "Anexo" del "Convenio de Berna".

Los países africanos no usan el mecanismo del "Anexo" ${ }^{\text {" }}$. De acuerdo a un

${ }^{53}$ Artículos 7, 25, 42, y 43 Law on Intellectual Property No 50/2005/QH11 of November 29, 2005 (Vietnam). Véase también, Artículo 29 Decree No 100/2006/NDCP of September 21, 2006, Detailing and Guiding the Implementation of a Number of Articles of the Civil Code and the Intellectual Property Law Regarding the Copyright and Related Rights (2006).

${ }^{54}$ Artículo 27 Copyright Protection Act No (22) of 1992, as amended by the Amending Law No (9) of 2005 (Jordania).

${ }^{55}$ Artículo 11 Copyright Protection Act $\mathrm{No}$ (22) of 1992, as amended by the Amending Law No (9) of 2005 (Jordania).

${ }^{56} \$ \$$ 50-54 Copyright Act 2005 (Act No 14 of 2005) on May 18, 2005, amending the Copyright Act 2000 (Act № 28 of 2000) (Bangladesh). Véanse: Azam, Mohammad Monirul, Intellectual Property, WTO, and Bangladesh (Dhaka, Bangladesh, New Warsi Book Corp., 2008), pp. 197-201; Hossain, Naznin - AkTAR, Sharifa, Intellectual Property Law (Dhaka, Bangladesh, Mirapura: Phātemā Bukas eṇụa Bhyārāiṭija, 2009), pp. 108 ss.

${ }^{57} \$$ 54-55 Copyright Act of B.E. 2537 (1994) (Tailandia). Véase: Consumers International, IP Watch List Report 2009, Thailand Report. Disponible en: http:// a2knetwork.org/reports2009/thailand (fecha de consulta: 1 de mayo de 2011), el cual consigna que este tipo de licencias es sumamente difícil de obtener en Tailandia.

${ }^{58}$ FOMETEU, Joseph, WIPO Study on Limitations and Exceptions for Copyright and 
reciente estudio sobre derechos de autor en países del África ${ }^{59}$, un continente que representa en conjunto el $0.3 \%$ de las exportaciones de libros del plane$\mathrm{ta}^{60}$, de ocho países analizados, solamente uno ha implementado el sistema de licencias obligatorias previsto en el "Anexo" del "Convenio de Berna". A pesar de no ser parte del Convenio, Uganda ha establecido excepciones al derecho de autor y, al mismo tiempo, implementado las disposiciones del "Anexo" en su derecho interno ${ }^{61}$. Otros cinco países apenas si disponen de excepciones y limitaciones a los derechos de autor: Ghana, Kenya, Mozambique, Marruecos, y Senegal ${ }^{62}$. Entretanto, como fue explicado, Egipto y Sudáfrica no han implementado el mencionado mecanismo sino una solución idiosincrática ${ }^{63}$. Entre los últimos países deberíamos mencionar también a Sudan, cuya legislación permite al gobierno emitir ordenes de publicación de una determinada obra por razones de interés público, con el pago de una compensación a los titulares de derechos ${ }^{64}$.

Los países en desarrollo de Latinoamérica tampoco usan el mecanismo del "Anexo" 65 . De acuerdo a las Naciones Unidas, en el 2011, de los 35 países del continente Americano 33 calificaban como países en desarrollo y, en consecuencia, potenciales usuarios del mecanismo diseñado en el "Anexo"66. En cambio, como fue ya mencionado, de acuerdo a los registros de la OMPI, sólo uno de esos países tomaría ventaja del "Anexo": Cuba ${ }^{67}$. Sin embargo, al

Related Rights for Teaching in Africa, Documento OMPI, SCCR/19/5 Oct. 26, 2009, p. 42.

${ }^{59}$ Armstrong y otros, Access to Knowledge in Africa: The Role of Copyright (Sudáfrica, UCT Press, 2010).

${ }^{60}$ Centro Regional para el Fomento del Libro en América Latina, el Caribe, España y Portugal-Cerlalc, El Espacio Iberoamericano del Libro 2010 (Santiago de Chile, Cerlalc, 2010), p. 100.

${ }^{61} \$ 17$ y 18 Copyright and Neighboring Rights Act 19 of 2006 (Uganda). Véanse: Kawooya, Dick - Kakungulu, Ronald - Akubu, Jeroline, Uganda, en ArmsTRONG y otros, cit. (n. 59), pp. 283 y 288.

${ }^{62}$ Armstrong y otros, cit. (n. 59), pp. 326-327.

${ }^{63}$ Véanse más abajo las notas 96 a 100 y su texto principal; y las notas 78 a 81 y su texto principal.

${ }^{64}$ Véase más arriba la nota 50 y su texto principal.

${ }^{65}$ Plazas, Arcadio, cit. (n. 8), p. 211.

${ }^{66}$ United Nations Statistics Division, Composition of Macro Geographical (Continental) Regions, Geographical Sub-Regions, and Selected Economic and Other Groupings (revisado el 26 de abril de 2011), disponible en http://unstats.un.org/unsd/methods/ m49/m49regin.htm\#ftnc (fecha de consulta: 11 de mayo de 2011).

${ }^{67}$ Declaration by the Republic of Cuba Relating to Articles II and III of the "Appendix" to the "Paris Act" (1971), 28 de junio de 2004. Disponible en: http:// www.wipo.int/treaties/en/notifications/berne/treaty_berne_238.html (fecha de consulta: 13 de julio de 2011). 
revisar la normativa de los países de la región es posible constatar que otros seis han establecido licencias obligatorias para la traducción en su derecho interno, si bien ellos no han notificado al director general de la OMPI. Algunos países han adoptado escuetas disposiciones en su legislación que resultan oscuras, ambiguas, e insuficientes para ser funcionales; este es el caso de El Salvador ${ }^{68}$, Honduras ${ }^{69}$ y Panamá ${ }^{70}$. No existe evidencia, sin embargo, de que tales países hayan emitido siquiera una licencia obligatoria. La normativa de implementación de Colombia ${ }^{71}$, México ${ }^{72}$ y la República Dominicana ${ }^{73}$, en cambio, está mejor elaborada y provee un régimen legal suficiente sobre licencias obligatorias. Sin embargo, tampoco existe evidencia de que tales países hayan emitido una de tales licencias.

A pesar de disponer de legislación de implementación, ni Colombia ni México sacan ventaja del mecanismo diseñado por el "Anexo". En el caso de Colombia, la autoridad competente ha omitido notificar al director general de la OMPI y, adicionalmente, sostiene la tesis de que el mecanismo previsto en su legislación interna de derechos de autor no está vigente por su propia negligente omisión ${ }^{74}$; en consecuencia, ninguna licencia obligatoria ha sido

${ }^{68}$ Artículo 77 del Decreto No 604 de 1993 Ley de fomento y protección de la propiedad intelectual (El Salvador).

${ }^{69}$ Artículo 122 Decreto 4-99-E, 2000, Ley del derecho de autor y de los derechos conexos, texto consolidado 2006 (Honduras).

${ }^{70}$ Artículo 84 Ley No 15 (De 8 de agosto de 1994) Ley sobre el derecho de autor $y$ derechos conexos (Panamá).

${ }^{71}$ Ley № 23 de 1982 sobre Derechos de autor, Diario Oficial, febrero 19, 1982 (Colombia). Véase: Ministerio de Gobierno (de Colombia), Los derechos de autor en Colombia (Bogotá, Ministerio de Gobierno, 1982); Rengifo García, Ernesto, Propiedad intelectual: El moderno derecho de autor (Universidad Externado de Colombia, 1996), pp. 178 et seq.

${ }^{72}$ Artículo 147 de la Ley federal del derecho de autor, Diario Oficial de la Federación, 24 de diciembre de 1996, texto consolidado a julio de 2003 (México); y, artículos 3843 Reglamento de la Ley Federal del Derecho de autor, Diario Oficial de la Federación, 22 de mayo de 1998, modificado el 14 de septiembre de 2005 (México).

${ }^{73}$ Ley No 65-00 de Derecho de autor, Gaceta Oficial, 24 de agosto de 2000 (República Dominicana); y, artículo 24 Decreto No 362-01 del 14 de marzo del 2001 que: Establece el reglamento de aplicación de la Ley $N^{\circ}$ 65-00 sobre derecho de autor (República Dominicana). Véanse: CASTrejon García, Gabino, Tratado teórico-práctico de los derechos de autor y de la propiedad intelectual (Mexico, CCD, 2001), pp. 102-105; Serrano Migallón, Fernando, Nueva Ley federal del derecho de autor (México, Editorial Porrúa - UNAM, 1998), p. 163.

${ }^{74}$ Dirección Nacional de Derecho de Autor, Colombia, Concepto 1-2010-7340, 21 de mayo de 2010. La decisión de la autoridad autoral colombiana erradamente subordina la eficacia de las disposiciones legales a la diligencia de las autoridades administrativas en cumplir con obligaciones internacionales. La licencia obligatoria prevista en la ley interna es válida, sin perjuicio de la posible responsabilidad internacional por la 
emitida $^{75}$. En el caso de México, su última notificación al director general de la OMPI tuvo lugar en 1984 y no fue renovada; además, el Tratado de libre comercio de Norte América (NAFTA, por sus siglas en inglés) ha establecido un nuevo requisito para la emisión de tales licencias, prohibiéndolas cuando las necesidades legítimas de copias o traducciones de la obra pudieran cubrirse mediante acciones voluntarias del titular del derecho, de no ser por obstáculos creados por las medidas de la parte que emite la licencia ${ }^{76}$. Pero tal omisión no representaría un serio problema porque, de acuerdo a las autoridades mexicanas entrevistadas, a pesar de que el mecanismo se encuentra implementado en la legislación interna desde hace muchísimos años ${ }^{77}$, nunca fue aplicado $^{78}$. No son claras las razones por las cuales el mecanismo carece de uso, pero las autoridades entrevistadas sospechan que la potencial utilidad del mecanismo es socavada por el costoso trámite y el limitado alcance del sistema de licencias ${ }^{79}$.

Los expertos tienden a estar de acuerdo en que el mecanismo diseñado en el "Anexo" no satisface las expectativas de los países en desarrollo, ni sus propios objetivos. De hecho, no ha producido ningún real mejoramiento en las condiciones de acceso a contenidos protegidos ${ }^{80}$, un problema persistente en los países en desarrollo ${ }^{81}$. Entre las principales críticas al "Anexo” se consignan sus reglas burocráticas, su limitado ámbito de aplicación, y excesivas

negligente omisión de la autoridad administrativa. En este caso, la situación es evitada por el hecho de que la misma autoridad que ha omitido notificar al director general de la OMPI y soporta la inaplicabilidad de las licencias obligatorias previstas en la ley es también la competente para emitir tales licencias. Véase: AwAD, Bassem - EL-GHERIANi, Moatasem - Abou Zeid, Perihan, Egypt, en Armstrong y otros, cit. (n. 59), p. 49, quien también sustenta, en una análoga situación en el derecho egipcio, la eficacia del mecanismo previsto en el derecho interno sin perjuicio de la eventual responsabilidad del estado por la omisión de obligaciones prevista en el derecho internacional.

${ }^{75}$ Rengifo García, Ernesto, cit. (n. 71), p. 178.

${ }^{76}$ Véase: North American Free Trade Agreement, 1992, U.S.-Can.-Mex., art. 1705.6 .

${ }^{77}$ Serrano Migallón, Fernando, cit. (n. 73), p. 161.

${ }^{78}$ Entrevista telefónica con don Marco A. Morales Montes, Director Jurídico, Instituto Nacional del Derecho de Autor (México) (27 de mayo de 2010).

${ }^{79}$ Ibíd.

${ }^{80}$ Drahos - Braithwaite, cit. (n. 10), pp. 77.

${ }^{81}$ Véase: Chon, Margaret, Copyright and Capability for Education: An Approach 'From Below', en Wong, Tzen - Dutrield, Graham (editores), Intellectual Property and Human Development: Current Trends and Future Scenarios, (Cambridge University Press, 2011), pp. 218-249, refiriéndose a la severa carencia de libros de estudio en los países en desarrollo y soportando la reforma al sistema de licencias obligatorias establecido en el "Anexo" del Convenio de Berna. 
medidas de resguardo a favor de los titulares de derechos ${ }^{82}$; en vez de ser un instrumento de desarrollo, el "Anexo" ha reducido la capacidad de los países en desarrollo para diseñar políticas públicas que provean una amplia diseminación del conocimiento. Sin embargo, dada su urgente necesidad, algunos países han implementado peculiares medidas que brida flexibilidad en su derecho interno, las cuales se reseñan a continuación.

\section{Los paises en desarrollo han buscado sus propias soluciones.}

Dada la inutilidad de las disposiciones del "Anexo", los países en desarrollo han adoptado soluciones alternativas dentro de su derecho interno a efectos de mitigar las limitaciones del mecanismo previsto en el "Convenio de Berna”. Existe un amplio rango de soluciones disponible en tales países, algunas de las cuales van más allá de lo que fue ambicionado por el "Anexo". Algunas de dichas soluciones están basadas en excepciones y limitaciones a los derechos autorales, cuya consistencia con la "prueba de los tres pasos" prevista en el "Convenio de Berna" es discutible. En otros casos, ha sido adoptado un mecanismo de licencias obligatorias más amplio o flexible que aquél previsto en el "Anexo", por ejemplo, permitiendo al gobierno la emisión de licencias para evitar el abuso monopólico o por otras razones de interés público. Varios países tienen un set de mecanismos para enfrentar el acceso a las obras protegidas con propósitos de favorecer el desarrollo, incluyendo excepciones, diversas licencias obligatorias, e incluso expropiación. Aun más radical, en algunos países, a pesar de estar vigente el plazo de protección de los derechos de autor, ciertas obras carentes de traducción entran al dominio público, permitiendo su uso por ley.

La principal estrategia de los países en desarrollo para satisfacer sus necesidades parece ser la adopción de excepciones y limitaciones. En Chile, por ejemplo, una reciente modificación legal incluyó tres excepciones específicamente previstas para la traducción de obras ${ }^{83}$ : una para usos personales ${ }^{84}$, otra para la traducción de fragmentos para fines educacionales ${ }^{85} \mathrm{y}$ otra para usuarios de bibliotecas ${ }^{86}$. Sin embargo, las excepciones previstas en países como Chile son aún bastante reducidas para satisfacer los propósitos de las disposiciones del "Anexo" ${ }^{\text {", }}$, por los requisitos que impone la "prueba de los

\footnotetext{
${ }^{82}$ BasalamaH, Salah, Compulsory Licensing for Translation: An Instrument of Development?, en IDEA, 40 (2000) 4, pp. 503-547

${ }^{83}$ Ley 17.336 Sobre propiedad intelectual, modificada por la Ley 20.435, Diario Ofcial, 4 de mayo de 2010 (Chile).

${ }^{84}$ Artículo 71 R Ley 17.336.

${ }^{85}$ Artículo 71 M Ley 17.336.

${ }^{86}$ Artículo 71 L Ley 17.336.

${ }^{87}$ De hecho, en el caso de Chile, durante la discusión de la ley que modificó re-
} 
tres pasos", la cual previene la traducción, publicación, y masiva distribución de obras completas. Como resultado, estas excepciones satisfacen objetivos significativamente limitados, usualmente sujeto a varias condiciones, tales como una limitación en la cantidad del uso, restricciones sobre la calidad del uso basadas en la naturaleza de la obra y del usuario, limitaciones basadas en la localización física de las obras, y las circunstancias en torno a las cuales las obras son empleadas. Mediante la simple utilización de excepciones y limitaciones a los derechos de autor, en consecuencia, los países están limitados e impedidos de satisfacer sus necesidades de desarrollo.

Algunos países han adoptado excepciones y limitaciones a los derechos de autor más amplias que permiten la traducción y publicación de un idioma a otro, las cuales es discutible si cumplen con la "prueba de los tres pasos" establecida en el "Convenio de Berna". Por ejemplo, China recientemente adoptó una nueva ley de derechos de autor que contempla varias disposiciones relativas a la traducción ${ }^{88}$ : una excepción permite la traducción y la reproducción de pequeñas porciones de una obra para efectos de investigación y docencia $^{89}$, y una licencia obligatoria permite el uso de las obras en textos de estudio $^{90}$. Además, una sensible excepción permite la traducción de las obras de autores chinos desde el han a algún otro idioma minoritario dentro del país ${ }^{91}$. Esta última excepción podría infringir la "prueba de los tres pasos", al permitir una traducción indiscriminada de obras sin compensación para el titular de los derechos, pero la eficacia de dicha disposición está circunscrita

cientemente la Ley de propiedad intelectual, fue introducida una propuesta de licencias obligatorias similar a la prevista en el "Anexo" del "Convenio de Berna", pero ella no prosperó por exigencias reglamentarias del proceso legislativo.

${ }^{88}$ Copyright Law of the People's Republic of China, as amended on February 26, 2010 (República Popular China). Véase: Xue, Hong, Intellectual Property Law in China (Países Bajos, Kluwer International, 2010), pp. 29-32.

${ }^{89}$ Artículo 22 (6) Copyright Law of the People's Republic of China, as amended on February 26, 2010 (República Popular China). Véase también el artículo 6 (3) Decree of the State Council of the People's Republic of China No 468: Regulations on Protection of the Right of Communication through Information Network, adopted at the 135 Executive Meeting of the State Council on May 10, 2006 (República Popular China).

${ }^{90}$ Artículo 23 Copyright Law of the People's Republic of China, as amended on February 26, 2010 (República Popular China). Véase también el artículo 8 Decree of the State Council of the People's Republic of China No 468: Regulations on Protection of the Right of Communication through Information Network, adopted at the 135 Executive Meeting of the State Council on May 10, 2006 (República Popular China).

${ }^{91}$ Artículo 22 (11) Copyright Law of the People's Republic of China, as amended on February 26, 2010 (República Popular China). Véase también el artículo 6 (5) Decree of the State Council of the People's Republic of China No 468: Regulations on Protection of the Right of Communication through Information Network, adopted at the 135 Executive Meeting of the State Council on May 10, 2006 (República Popular China). 
fundamentalmente a la nacionalidad del autor, así como las lenguas de origen y traducción de la obra. Estas circunstancias mitigan significativamente los riesgos de un conflicto internacional contra China sustentado en infracción a la "prueba de los tres pasos", pero, al mismo tiempo, impiden a este país la consecución de los fines ambicionados por el "Anexo" con respecto a autores foráneos y obras en idiomas extranjeros.

En adición a las excepciones, algunos países han adoptado un esquema de licencia obligatoria más permisivo que aquél previsto en el "Anexo". Como ya fue mencionado, este es el caso de los Emiratos Árabes Unidos ${ }^{92}$. También parece ser el caso de Sudáfrica ${ }^{93}$, cuya ley de derechos de autor, en vez de adoptar una excepción para traducción caso a caso, autoriza la traducción de las obras en relación con prácticamente toda otra excepción ${ }^{94}$. La ley también confiere competencia al Tribunal de Derechos de Autor de Sudáfrica para emitir licencias obligatorias cuando el titula de los derechos ha rehusado hacerlo sin razonable motivo ${ }^{95}$. Además, la ley permite al gobierno adoptar regulaciones respecto de la circulación, presentación, o exhibición de obras, lo que, según algunos autores, permitiría un "esquema de licencias no voluntarias" $"$.

Algunos países han adoptado en su derecho interno un régimen general de licencias obligatorias que permite la emisión de ellas por razones de interés público. Este es, como se ha mencionado, el caso de Sudan ${ }^{97}$ y Siria ${ }^{98}$, así como de Bolivia. Este último país no ha implementado el mecanismo previsto en el "Anexo", en cambio, junto a algunas excepciones y limitaciones al derecho de autor previstas en su derecho interno y en el derecho comunitario de la Comunidad Andina ${ }^{99}$, la ley de derechos de autor de Bolivia autoriza al gobierno para expedir licencias obligatorias para el uso de una obra protegida

${ }^{92}$ Véase más arriba la nota 49 y su texto principal.

${ }^{93}$ Copyright Act No 98 of 1978, as amended in 2002 (Sudáfrica). Véase: SCHONWETter, Tobias - Ncube, Caroline - Chetty, Pria, South Africa, en Armstrong et al, cit. (n. 59), p. 243.

${ }^{94} \$ 12$ (11) Copyright Act No 98 of 1978, as amended in 2002 (Sudáfrica).

${ }^{95}$ \%5 29-36 Copyright Act No 98 of 1978, as amended in 2002 (Sudáfrica).

${ }^{96} \$ 45$ Copyright Act No 98 of 1978, as amended in 2002 (Sudáfrica). Véase: SCHONWETTER y otros, cit. (n. 93), p. 243.

${ }^{97}$ Véase más arriba la nota 50 y su texto principal.

${ }^{98}$ Véase más arriba la nota 51 y su texto principal.

${ }^{99}$ Artículo 24 Ley No 1322 de 1992: Ley de derecho de autor, Gaceta Oficial, 27 de abril de 1992 (Bolivia); y, artículos 21, 22, 24-27 Decisión No 351 Régimen común sobre derecho de autor y derechos conexos, adoptada por la Comisión del Acuerdo de Cartagena, el 17 de diciembre de 1993, Gaceta Oficial de la Comunidad Andina No 145, 21 de diciembre de 1993. 
por razones de interés público, con el pago de compensación ${ }^{100}$. No hay evidencia, sin embargo, de que se haya expedido siquiera una de tales licencias. Además, no es claro hasta qué punto la respectiva disposición de la ley subsiste frente al régimen común sobre derechos de autor de la Comunidad Andina ${ }^{101}$, de la cual Bolivia es parte ${ }^{102}$.

La adopción de una licencia obligatoria general por razones de interés público dentro del derecho interno, la cual se sobrepone a la licencia permitida por el "Anexo", es una estrategia común usada por varios países en desarrollo. Este es el caso de la República Dominicana ${ }^{103}$ y Jordania ${ }^{104}$. La ley de derechos autorales de República Dominicana establece no sólo excepciones y una licencia obligatoria inspirada en el "Anexo", sino que también una licencia obligatoria general. De acuerdo a la ley de derechos de autor de Jordania, el gobierno puede emitir una licencia obligatoria para usar una obra por razones de interés público, con el pago de una compensación ${ }^{105}$. No es claro, sin embargo, hasta qué punto la coexistencia de la licencia obligatoria general por razones de interés público y la licencia obligatoria de acuerdo al "Anexo" priva a la segunda de significancia; si un país tiene ambas licencias obligatorias, parece no haber razón para usar aquella prevista en el "Anexo" cuando la disponible por razones de interés público permite alcanzar resultados similares con menos trámites y requisitos.

Algunos países han ido más allá a efectos de satisfacer sus necesidades de desarrollo mediante la implementación de licencias obligatorias por razones de interés público sin compensación para los titulares de derechos afectados. Cuba, por ejemplo, se ha habilitado a sí mismo para hacer uso del mecanismo previsto en el "Anexo", pero, en vez de implementar éste, ha adoptado una verdadera excepción a los derechos de autor con los mismos objetivos previstos en el "Anexo" y similares medidas de resguardo a los derechos de

${ }^{100}$ Artículo 25 Ley No 1322 de 1992: Ley de derecho de autor, Gaceta Oficial, 27 de abril de 1992 (Bolivia).

${ }^{101}$ Artículo 32 Decisión No 351 Régimen común sobre derecho de autor y derechos conexos, adoptada por la Comisión del Acuerdo de Cartagena, el 17 de diciembre de 1993, Gaceta Oficial de la Comunidad Andina No 145, 21 de diciembre de 1993.

102 "Acuerdo de Cartagena”, Bogotá, de 28 de mayo de 1969, mediante el cual se crea la Comunidad Andina, actualmente integrada por Bolivia, Colombia, Ecuador, y Perú.

${ }^{103}$ Véase más arriba la nota 72 y su texto principal.

${ }^{104}$ Véase más arriba la notas 54 y 55 , así como su texto principal.

${ }^{105}$ Artículo 48 Ley No 65-00 de Derecho de autor, Gaceta Oficial, 24 de agosto de 2000 (República Dominicana); y, artículos 25-28 Decreto No 362-01 del 14 de marzo del 2001 que establece el reglamento de aplicación de la Ley No 65-00 sobre Derecho de autor (República Dominicana). 
los titulares, a excepción de una compensación ${ }^{106}$. Expertos de la isla sostienen que el mecanismo ha sido empleado para superar el bloqueo comercial impuesto por los Estados Unidos y terceros países a instancias de éste, y que ha permitido un importante número de traducciones, especialmente en las áreas de la salud y las ciencias ${ }^{107}$; pero el mecanismo también ha sido cuestionado en su consistencia con los compromiso internacionales en materia de derechos de autor asumidos por $\mathrm{Cuba}^{108}$. Un mecanismo análogo parece estar disponible bajo la ley sobre derechos de autor de Vietnam, la cual permite al gobierno adoptar restricciones, incluso licencias obligatorias, sobre los derechos exclusivos, sin mención a compensación alguna ${ }^{109}$. Curiosamente, tanto Cuba como Vietnam están habilitados ante el director general de la OMPI, lo cual suscita preocupación en cuanto a la adecuada comprensión que tales países tienen acerca del mecanismo previsto en el "Anexo" del "Convenio de Berna”, ya que aquellos que han implementado en su legislación interna difícilmente cumplen con los estándares, procedimientos, y requisitos establecidos en el tantas veces mencionado instrumento internacional.

La extinción de los derechos de autor sobre obras que carecen de traducción al idioma local es otra medida que ciertos países en desarrollo han introducido en su legislación a efectos de satisfacer sus necesidades. Egipto y Kuwait han hecho esto ${ }^{110}$. En el caso de Egipto, por ejemplo: por un lado, la ley ha establecido un sistema de licencias obligatorias que se ajusta al "Anexo" del "Convenio de Berna", con algunas simplificaciones ${ }^{111}$; y, por otro lado, la protección de los derechos de autor en obras sin traducción al árabe se extingue, a menos que la traducción quede disponible dentro de los tres años siguientes a la primera publicación de la obra ${ }^{112}$. En este último caso,

${ }^{106}$ Véase más arriba la nota 52 y su texto principal.

${ }^{107}$ Entrevista con Lillian Álvarez y Alejandro Rivero (Cuba) (29 de junio de 2010).

${ }^{108}$ Véase: VAldÉs Diaz, Caridad del Carmen, La Facultad de reproducción, en Moreno Cruz, Marta y otros, Selección de lecturas de derecho de autor (La Habana, F. Varela, 2000), p. 105.

${ }^{109}$ Artículo 7 (3) Law on Intellectual Property No 50/2005/QH11 of Nov. 29, 2005 (Vietnam).

${ }^{110}$ Artículos 14, 16 (1), y 16 (2) Law No 64 of 1999 Concerning Intellectual Property Rights, Dec. 29, 1999 (Kuwait).

${ }^{111}$ Artículo 170 Law on the Protection of Intellectual Property Rights 82 of 2002, Official Gazette, Jun. 2, 2002 (Egipto). Véase Prime Minister Decree No 497 of 2005 On Issuing the Executive Regulations for Book III Of Law No (82) of 2002 on the Protection of Intellectual Property Rights.

${ }^{112}$ Artículo 148 Law on the Protection of Intellectual Property Rights 82 of 2002, Official Gazette, 2 de junio de 2002 (Egipto): "copyright [...] shall lapse with regards to the translation of that work into the Arabic language, unless the author or the translator bimself exercises this right directly or through a third party within three years of the date 
las obras ingresan al dominio público y una licencia, obtenida del gobierno junto al pago de una tarifa, autoriza la explotación comercial y profesional por cualquier interesado ${ }^{113}$. Entonces, en teoría, una licencia obligatoria como la prevista en el "Anexo" puede ser requerida para traducir una obra dentro de los tres años desde su publicación y, después de esos tres años, una licencia puede ser requerida del gobierno para hacer traducción de una obra que ingreso al dominio público por carecer de traducción al árabe ${ }^{114}$. Algunos expertos han expresado preocupación por la falta de consistencia de esta regulación con el derecho internacional; sin embargo, también se ha controvertido la eficacia real del mecanismo, pues él es prácticamente desconocido por los editores locales y, además, las diversas iniciativas públicas existentes en el país para la traducción de obras al árabe no hacen uso de tal mecanismo, sino que de licencias voluntarias ${ }^{115}$.

El abundante número de países en desarrollo que han adoptado mecanismos idiosincráticos para permitir un amplio acceso a obras protegidas también sugiere la ineficacia de las disposiciones del "Anexo" del "Convenio de Berna”. Es, además, un resultado poco deseable. Primero, porque no es claro que cada una de las diferentes soluciones adoptadas en derecho interno de los países en desarrollo cumpla con los instrumentos internacionales en materia de derechos autorales, lo cual crea un riesgo de conflicto ante la Organización Mundial de Comercio, cuyo sistema de resolución de controversias es aplicable al caso. Segundo, precisamente por dicho riesgo, se produce un desincentivo entre las autoridades locales para dar efectivo uso al mecanismo disponible en su legislación interna; de hecho, la data sugiere que tanto las autoridades como los potenciales usuarios locales son reacios a tomar ventaja de estos mecanismos. Tercero, las características sui generis de las soluciones locales afectan la armonización internacional y obstaculiza la adopción de prácticas estandarizadas entre los actores de ambos sectores, el educacional y el editorial. Pero, por sobre todo, esta situación menoscaba el propósito de proveer a los países en desarrollo de una solución efectiva para permitirles una amplia diseminación del conocimiento.

En síntesis, el mecanismo del "Anexo" parecería proveer una solución

of first publication of the original or translated work") Véase: Aвdel LATIF, Ahmed, Egypt's Role in the A2K Movement: An Analysis of Positions and Policies, en Rizk, Nagla - Shaver, Lea, Access to Knowledge in Egypt: New Research on Intellectual Property, Innovation and Development (Londres, Bloomsbury Academic, 2010), p. 39.

${ }^{113}$ Artículo 183 Law on the Protection of Intellectual Property Rights 82 of 2002, Official Gazette, 2 de junio de 2002 (Egipto).

${ }^{114}$ El SAghir, Hossam A., Intellectual Property Law in Egypt (La Haya, Kluwer International, 2009), pp. $45-46$ y 65.

${ }^{115}$ Aw AD y otros, cit. (n. 74), p. 49. 
parcial a sólo un muy reducido número de países en desarrollo, los cuales han notificado al director general de la OMPI su intención de hacer uso del mecanismo. Sin embargo, no hay evidencia de su uso efectivo por tales países siquiera. Varios otros países han dejado de notificar o renovar su notificación a la OMPI porque el mecanismo ha probado ser inútil, mientras otros países han adoptado mecanismos idiosincráticos en su derecho interno. En general, la data sugiere que el "Anexo" del "Convenio de Berna" ha fracasado en satisfacer las necesidades de desarrollo de aquellos países en desarrollo.

\section{El "Anexo" no provee una solución para minorias,}

En los países en desarrollo, las disposiciones del "Anexo" del "Convenio de Berna" suscitan alguna incertidumbre acerca de su aplicación a idiomas de ciertas minorías lingüísticas. El "Anexo" autoriza a los países para expedir licencias obligatorias para la traducción de obras a un "idioma de uso general en el país que otorga la licencia"116. El "Anexo" va más allá del simple idioma oficial de un país, pero aún así no ofrece certidumbre respecto de qué es o no un lenguaje de uso general. Por ejemplo, entre los años 2005 y 2009, de acuerdo a estadísticas de ISBN, sólo 323 libros fueron publicados en 14 lenguas Amerindias en toda Iberoamérica (i.e., Latinoamérica, Portugal, y España) ${ }^{117}$. En contraste, sólo en Colombia hay 64 lenguas Amerindias y varios dialectos ${ }^{118}$. Claramente, el número de obras publicadas es incapaz de satisfacer las necesidades de las comunidades nativas de las Américas. Un nuevo instrumento que provea un mecanismo apropiado para el desarrollo debería ser más flexible respecto de los idiomas a los cuales una obra puede ser traducida, permitiéndolo inclusive en caso de idiomas que no sean de uso generalizado en el país respectivo.

El acceso lingüístico a obras protegidas por el derecho de autor es un asunto apremiante no sólo en los países en desarrollo sino también en países desarrollados ${ }^{119}$. En España, por ejemplo, junto con el "castellano" (usualmente conocido como "español") existen varios otros idiomas regionales en uso -aranés, catalán, gallego, valenciano, y vasco, entre otros-, algunos de

${ }^{116}$ Véase: General Report of Paris Conference, en World Intellectual Property Organization, cit. (n. 34), párrafo 30.

${ }^{117}$ Centro Regional para el Fomento del Libro en América Latina, el Caribe, España y Portugal, Cerlalc, cit. (n. 60), p. 62.

${ }^{118}$ Ibíd. p. 76.

${ }^{119}$ De hecho, durante la conferencia diplomática que concluyó con la modificación simultánea de la "Convención universal de derechos de autor" y la adopción de un “Anexo" en el "Convenio de Berna” a través del Acta de París de 1971, Canadá expresó una preocupación similar en torno a la relatividad del concepto de países en desarrollo y desarrollados. Véase: Report of the General Repporteur of the Universal Copyright Convention, párrafos 58-59, en UNESCO, cit. (n. 32), párrafo 22. 
ellos prohibidos durante la larga dictadura de $\mathrm{Franco}^{120}$. Sin embargo, las comunidades que hablan dichos idiomas no pueden sacar partido del "Anexo", por estar localizadas en un país desarrollado ${ }^{121}$. Este es también el caso de la población navajo y hawaiana de los Estados Unidos, con las comunidades hablantes de ladino y esloveno en Italia, y con los inuit en Canadá, entre otros. Las minorías lingüísticas enfrentan serios desafíos en aquellos países, similares a aquellos enfrentados por países en desarrollo. Esto evidencia que el "Anexo" equivocadamente asume que el grado de desarrollo de los países es homogéneo y que no existirían necesidades especiales que requieran ser satisfechas en países que califican de desarrollados.

Si el derecho de autor bloquea la traducción de obras a un idioma minoritario, los hablantes de tal idioma se ven forzados a dejar éste y adoptar una lengua de mayor uso, corriendo el riesgo de condenar su propio idioma a la extinción ${ }^{122}$. Esto suscita preocupación en torno al derecho a la identidad de los miembros de tal comunidad idiomática, así como acerca de la protección de la diversidad cultural. Es tanto un asunto individual como social. El "Anexo" del "Convenio de Berna" ha previsto flexibilidades para los países en desarrollo, de modo de facilitar el acceso de su población a las obras para mejorar sus condiciones sociales, económicas, y culturales; si otras comunidades enfrenta dilemas similares, el "Anexo" no debería obstaculizar la adopción de una solución análoga. De otro modo, se crean desventajas para el desarrollo de tales comunidades.

De acuerdo con la recientemente adoptada Convención sobre la diversidad cultural $^{123}$, los gobiernos están obligados a proteger y promover la diversidad cultural, incluyendo la diversidad lingüística como un componente esencial de la primera. La mencionada Convención no requiere ninguna medida en particular con respecto a los derechos autorales y, en cambio, reconoce la importancia de la propiedad intelectual para incentivar la participación en la creatividad cultural ${ }^{124}$. Sin embargo, desde que los derechos autorales son

${ }^{120} \mathrm{BENET}$, Josep, Catalunya sota el règim franquista: Informe sobre la persecució de la llengua i la cultura de Catalunya pel régim del general Franco (Barcelona, Blume, 1978); Benet, Josep, L'intent franquista de genocidi cultural contra Catalunya (Barcelona, Publicacions de l'Abadia de Montserrat, 1995).

${ }^{121}$ En 2009, el 78,32\% de las publicaciones españolas fueron en castellano; 9,55\% en catalán; $1,92 \%$ en gallego; $1,85 \%$ en vasco; $1,27 \%$ en valenciano; y un $0,1 \%$ en otras lenguas peninsulares. Véase: Centro Regional para el Fomento del Libro en América Latina, el Caribe, España y Portugal, Cerlalc, cit. (n. 60), pp. 60-61.

${ }^{122}$ Austin, Peter - Simpson, Andrew (editores), Endangered Languages (Hamburgo, Helmut Buske Verlag, 2007), p. 5.

${ }^{123}$ Convención sobre la protección y promoción de la diversidad de las expresiones culturales, UNESCO, Paris, 20 de octubre 2005.

${ }^{124}$ Desurmont, Thierry, Considerations on the Relationship between the Conven- 
esencialmente "derechos privados" 125 , mientras que la diversidad cultural es patrimonio común de la humanidad que debe ser protegido y preservado para el beneficio de todos ${ }^{126}$, no es difícil suponer que, en caso de existir un conflicto de intereses, la diversidad cultural prevalecerá sobre los derechos autorales.

Un nuevo intento de proveer flexibilidades en el régimen internacional de los derechos de autor debe ser consistente con las obligaciones que los países han asumido en orden a proteger y promover la diversidad cultural. Consecuentemente, el "Anexo" debe reconsiderar si el acceso lingüístico es sólo un problema de idiomas de uso general entre los países en desarrollo o un problema más amplio que podría incluir otros idiomas e incluso países desarrollados. Esto puede transformarse en un asunto urgente en los próximos años, ya que la preservación de los idiomas enfrenta serios desafíos en un entorno globalizado que acelera la pérdida de diversidad cultural y lingüística.

\section{El "Anexo" suscita dudas respecto de su aplicación a obras digitales.}

A la época de adoptarse el "Anexo" del "Convenio de Berna", Internet y la digitalización de contenidos no era una realidad, no al menos en las proporciones en que lo es hoy. De acuerdo a la Unión Internacional de Telecomunicaciones, existen alrededor de 2 billones de usuarios de Internet en el mundo: un 30\% de la población global ${ }^{127}$. La tecnología ofrece una producción y distribución de contenidos expedita y a bajo costo, la que, paradojalmente, es asimétricamente disponible en el mundo, más para las personas de países desarrollados y menos para aquellos en países en desarrollo. Algunos países en desarrollo no han aún priorizado sus políticas públicas en relación a Internet, incluso como herramienta que permite proveer acceso al conocimiento, porque las tecnologías resultan aún inasequibles; para estos países, las políticas de Internet parecen un objetivo para un futuro algo lejano. No obstante, el progresivo descenso en los costos de la tecnología sugiere que

tion on the Protection and Promotion of the Diversity of Cultural Expressions and the Protection of Authors' Rights, en Revue Internationale du Droit d'Auteur, 2 (2006), p. 208.

125 "Preámbulo" del "Acuerdo sobre los ADPIC": "Reconociendo que los derechos de propiedad intelectual son derechos privados".

126 "Preámbulo" de la Convención sobre la protección y promoción de la diversidad de las expresiones culturales, reconociendo que "la diversidad cultural constituye un patrimonio común de la humanidad que debe valorarse y preservarse en provecho de todos".

${ }^{127}$ International Telecommunication Union, Key Global Telecom Indicators for the World Telecommunication Service Sector, disponible en: http://www.itu.int/ ITU-D/ict/statistics/at_glance/KeyTelecom.html (fecha de consulta: 15 de mayo de 2011). 
las oportunidades que ella ofrece pronto estarán también disponibles para personas de países menos desarrollados. Pero, ¿es aplicable el mecanismo previsto en el "Anexo" al entorno en línea?

El "Anexo" del "Convenio de Berna" podría sugerir que éste no provee un marco legal de flexibilidades para el entono en línea. De hecho, las disposiciones del "Anexo" limitan sus efectos al entorno analógico cuando expresamente dice que permite la traducción y reproducción de obras “impresas o cualquier otra forma análoga de reproducción" 128 , lo cual sugiere que las formas digitales de reproducción están excluidas del ámbito de aplicación del "Anexo". Esta exclusión explicaría algunas disposiciones adoptadas en el "Anexo" que tienen un marcado carácter territorial y que parecen inapropiadas para el entorno en línea, tal como la exigencia de que la traducción sea efectuada por nacionales del país que emite la licencia ${ }^{129}$, la prohibición a las exportaciones ${ }^{130}$, la hipótesis de ediciones "out of print" ${ }^{\text {"131 }}$, el agotamiento de existencias ${ }^{132}$ y las ventas in situ ${ }^{133}$.

A pesar de las alegaciones anteriores, las disposiciones del "Anexo" de "Convenio de Berna" son plenamente funcionales en el entorno en línea ${ }^{134}$. De hecho, ni el Convenio ni ningún otro instrumento internacional subsecuente a su adopción -tal como el Acuerdo sobre los ADPIC o los "Tratados Internet" de la OMPI, todos adoptados en un momento en el cual la Internet había crecido lo suficiente para estar prevenidos de sus efectos en materia de derechos autorales- han excluido la aplicación del "Anexo" al entorno en línea. Además, los términos y provisiones del "Anexo" tienen un significado tecnológicamente neutral, que refieren a procesos en vez de a una determinada tecnología, tal como las expresiones traducción y reproducción. Es verdad que el "Anexo" incluye algunas limitaciones, pero ellas no están diseñadas para excluir su aplicación del entorno en línea o de obras en formato digital sino para garantizar que el ámbito de aplicación de las flexibilidades quede reducido en beneficio de determinados países que califican para sacar ventaja del mismo "Anexo"; varias de dichas ventajas tienen una aplicación territorial que puede ser preservada mediante medidas tecnológicas, mientras que

\footnotetext{
${ }^{128}$ Artículos II (1), II (2) (a), y III (7) del “Anexo" del Convenio de Berna.

${ }^{129}$ Ibíd., artículos. IV (4 (a) y IV (5).

${ }^{130}$ Ibíd., artículo IV (4) (a).

${ }^{131}$ Ibíd., artículo II (2) (b).

${ }^{132}$ Ibíd., artículo II (6).

${ }^{133}$ Ibíd., artículo III (2) (a).

${ }^{134}$ FoMETEU, Joseph, cit. (n. 58), pp. 21-22, quien expresa que las licencias obligatorias previstas en el "Anexo" del "Convenio de Berna" aplican a cualquier obra susceptible de ser impresa, y sugiriendo que podría a las versiones digitales, si éstas pudiesen ser controladas como el "Anexo" requiere.
} 
otras de dichas limitaciones tienen el sentido de restringir la disponibilidad de las obras, lo cual puede también ser garantizado en el entorno en línea. En consecuencia, apropiadamente analizado, el "Anexo" del "Convenio de Berna” permite a los países en desarrollo sacar ventajas de sus disposiciones tanto para entornos en línea como no.

La documentación de la OMPI corrobora que las disposiciones del "Anexo" pueden aplicarse al entorno en línea y, consecuentemente, los países en desarrollo pueden sacar ventaja del desarrollo tecnológico en la implementación de dichas disposiciones. De acuerdo a la "Guía" de la OMPI, la frase "impresa o en cualquier otra forma análoga de reproducción" no tendría el propósito de excluir lo digital sino el sentido de que el mecanismo puede ser usado respecto de cualquier obra "similar", tales como libros y material impreso, por oposición a filmes y grabaciones ${ }^{135}$. Esto aparece ratificado por otra cláusula del mismo "Anexo" que hace una inequívoca distinción entre "impresa o en cualquier otra forma análoga de reproducción" y "fijaciones audiovisuales" ${ }^{136}$. Finalmente, usando una interpretación teleológica, de acuerdo a las normas sobre interpretación de los tratados de la Convención de Viena ${ }^{137}$, la "Guía" de la OMPI agrega que lo que es realmente importante es "elpropósito de la traducción, esto es la enseñanza, estudio, e investigación"138, sugiriendo que mientras el uso satisfaga dichos fines la forma de la obra resulta irrelevante.

Para estudiosos del derecho internacional de autor, la aplicación del las disposiciones del "Anexo" del "Convenio de Berna" al entorno en línea y las obras digitales es discutible. Para algunos autores contemporáneos a la adopción del instrumento, este no era un tema siquiera ${ }^{139}$. Sin embargo, para la mayor parte de los expertos la mención a "impresa o en cualquier otra forma análoga de reproducción" no estaba destinada a excluir las obras en formato digital; dicha mención permite la traducción y reproducción de cualquier obra escrita por oposición a grabaciones ${ }^{140}$. Sólo más tarde, en los años ochenta,

${ }^{135}$ World Intellectual Property Organization, cit. (n. 14), p. 153.

${ }^{136}$ Artículo III (7) del “Anexo" del “Convenio de Berna”. Véase: World Intellectual Property Organization, cit. (n. 14), p. 165.

${ }^{137}$ Artículo 31 (1) Convención sobre el derecho de los tratados, suscrita en Viena el 23 de mayo de 1969, U.N. Doc A/CONF.39/27 (1969), 1155 U.N.T.S. 331.

${ }^{138}$ World Intellectual Property Organization, cit. (n. 14), p. 153.

${ }^{139}$ Véase, e.g., Lipszyc, Delia, La Conferencia de Revisión de las Convenciones de Berna y Universal (Paris, Julio de 1971): Enfoque Argentino (Buenos Aires, CISAC, 1975), passim.

${ }^{140}$ Véanse: Ulmer, Eugen, cit. (n. 24), pp. 360 y 369; STEW ART, S. M., International Copyright and Neighbouring Rights (Londres, Butterworth, 1983), pp. 164 y 171; Nordeman - Vinck - Hertin - Meyer, International Copyright and Neighboring Rights Law: Commentary with Special Emphasis on the European Community (Alema- 
una interpretación distinta de las disposiciones del "Anexo" vino a aparecer, de acuerdo con la cual las disposiciones del "Anexo" impedían la traducción y reproducción de obras en formato digital ${ }^{141}$. Esta interpretación carece de todo sustento, tanto en los textos como en los reportes de las conferencias diplomáticas en que se suscribieron el "Acta de París" del "Convenio de Berna" como la revisión de la Convención universal de derechos de autor ${ }^{142}$, apenas si de una caprichosa interpretación de la expresión "análoga" como antónima de digital, un significado difícilmente razonable en $1971^{143}$. Des-

nia, VCH, 1990), pp. 302-303; Desbois - FrançON - Kéréver, Les Conventions Internationales du Droit d'Auteur et des Droits Voisins (París, Dalloz, 1976), pp. 295297. Véase también: Desbois, Henri, La Conférence Diplomatique de Révision des Conventions de Berne et de Genève, en Revue Internationale du Droit d'Auteur, 68 (abril de 1971), pp. 38-39.

${ }^{141}$ Véanse: Ricketson, Sam, cit. (n. 22), p. 638; Ricketson, Sam, WIPO Study on Limitations and Exceptions of Copyright and Related Rights in the Digital Environment, Documento OMPI, SCCR/9/7 April 5, 2003, p. 33; Ricketson, Sam - GinsBURG, Jane C., cit. (n. 22), párrafo 14.61; FICSOR, Mihály, Copyright and Transfer of Knowledge, en Copyright Bulletin (UNESCO), 17 (Unesco, 1983) 3, p. 15. Este último, posteriormente, ha mitigado su rechazo, en FiCSOR, Mihály, The Law of Copyright and the Internet: the 1996 WIPO Treaties, Their Interpretation, and Implementation (Nueva York, Oxford University Press, 2002), pp. 278-280; y, Ficsor, Mihály, Limitaciones y excepciones al derecho de autor en el entorno digital (Bogotá, Dirección Nacional de Derechos de Autor, CERLALC, 2008), pp. 32-33.

${ }^{142}$ De hecho, el reporte general de la conferencia diplomática en que se adoptó el "Acta de Paris" del "Convenio de Berna" no sustenta la exclusión de las obras en formato digital ni provee explicación alguna sobre las disposiciones del "Anexo" al respecto. En cambio, el reporte general de la Convención Universal sobre Derechos de Autor analiza extensamente sus disposiciones análogas a las del Anexo. De acuerdo a él, la traducción y reproducción se refieren a escritos, pero se excluyen "las grabaciones de sonido y cualquier otro formato excepto aquéllos susceptibles de ser leídos o de otro modo visualmente percibidos". Compárense General Report of Paris Conference, en World Intellectual Property Organization, cit. (n. 34), párrafos 27-43, con Report of the General Repporteur of the Universal Copyright Convention, párrafos 58-59, en UNESCO, cit. (n. 32), párrafos 87 y 112.

${ }^{143}$ Quienes sustentan que el "Anexo" del "Convenio de Berna" no permite la traducción y reproducción de obras en formato digital descansan su argumento en el significado de la expresión "análogo" como opuesto a digital. Sin embargo, dicho significado es errado pues: i) el Convenio emplea la expresión “análogo" en varias otras de sus disposiciones con el propósito de permitir una interpretación extensiva, no para excluir las tecnologías digitales; ii) en inglés, francés y español la primera acepción de la palabra análogo es similar, parecido, o comparable; de hecho, el uso de la expresión análogo como opuesto a las tecnologías digitales o computacionales no ha sido aprobado aún, al menos por la Real Academia de la Lengua Española; iii) la dicotomía entre análogo y digital, de hecho, sólo tuvo lugar a partir de los años ochenta, precisamente cuando surgió la interpretación restrictiva de las disposiciones del Anexo. 
afortunadamente, esta última y sin fundamentos su interpretación ha ejercido inmerecida influencia entre los expertos, quienes la repiten o sustentan sin cuestionamientos $^{144}$, inclusive entre aquellos que apoyan la inclusión de flexibilidades para fines de desarrollo ${ }^{145}$. Como resultado de ello, existe una profundamente arraigada equivocación en orden a que el "Anexo" no provee suficiente maniobrabilidad para aplicar sus disposiciones al entorno en línea $y$ a las obras en formato digital.

El "Anexo" del "Convenio de Berna" permite la emisión de licencias obligatorias para la traducción y reproducción de obras en formato digital disponibles en idioma extranjero a idiomas de uso general en el territorio de países en desarrollo. Sus disposiciones no prohíben el licenciamiento de tales obras, lo cual socavaría el propósito del "Anexo", al privar a los países en desarrollo de una tecnología capaz de proveer una solución efectiva para una amplia difusión de contenidos. Sin embargo, el “Anexo" ganaría en certidumbre si estableciese inequívocamente su plena aplicabilidad a las obras en formato digital. Ello brindaría a los países en desarrollo certidumbre acerca del potencial empleo de las disposiciones del "Anexo" en relación con el empleo de nuevas tecnologías para proveer acceso a las obras ${ }^{146}$.

${ }^{144}$ Véanse, por ejemplo: Monroy Rodríguez, Juan Carlos, Necesidad de nuevas limitaciones o excepciones para facilitar la digitalización y puesta a disposición de obras protegidas en el marco de la educación virtual", en Revista La Propiedad Inmaterial, 14 (2010), pp. 195-208; Monroy Rodríguez, Juan Carlos, WIPO Study on the Limitations and Exceptions to Copyright and Related Rights for the Purpose of Educational and Research Activities in Latin America and the Caribbean, Documento OMPI, SCCR/19/4 Sep. 30, 2004, pp. 48, 49 y 237. Véanse también, SENG, Daniel, WIPO Study on the Copyright Exceptions for the Benefit of Educational Activities for Asia and Australia, Documento OMPI, SCCR/19/7, Oct. 29, 2009, pp. 16 y 18; y ANTEQUERA, Ricardo, Las Limitaciones y Excepciones al Derecho de Autor y los Derechos Conexos en el Entorno Digital, Document OMPI-SGAE/DA/ASU/05/2, Oct. 26, 2005.

${ }^{145}$ Véase, por ejemplo: Fometeu, Joseph, cit. (n. 58), pp. 21-22. Véase también, Colombet, Claude, Grandes principios del derecho de autor y los derechos conexos en el Mundo: Estudio de Derecho comparado (3a edición, Madrid, UNESCO - CINDOC, 1997), p. 180.

${ }^{146}$ No obstante lo cual, véase artículo 11 de la Copyright Protection Act $\mathrm{N}^{\circ}(22)$ of 1992 (Jordan), as amended by the Amending Law No (9) of 2005, que establece una licencia obligatoria para traducción y reproducción de obras impresas o en cualquier otra forma al árabe; y, Decree of the State Council of the People's Republic of China No 468 : Regulations on Protection of the Right of Communication through Information Network, adopted at the 135 Executive Meeting of the State Council on May 10, 2006 (República Popular China), que impone un sistema de licencias obligatorias para la traducción y uso de obras en el entorno en línea, aun cuando limitado a las obras de autoría china. 


\section{JUSTIFICACIÓN DE UN NUEVO INSTRUMENTO PARA NECESIDADES DE DESARROLLO}

El solo hecho de que el "Anexo" no satisface las necesidades de los países en desarrollo debería ser razón suficiente para justificar la adopción de un nuevo instrumento que cumpla con tal propósito. Tal como se ha mencionado, los países en desarrollo hacen ningún o un limitadísimo uso del mecanismo diseñado por el "Anexo" por, entre otras consideraciones, sus burocráticos requisitos, limitadas ventajas, y altos costos transaccionales. Además, el "Anexo" crea alguna incertidumbre jurídica sobre su aplicación en entornos en línea y elude proteger las minorías culturales, tanto en países en desarrollo como desarrollados. No obstante, esta sección introduce dos nuevos argumentos en favor de la adopción de un nuevo instrumento que satisfaga necesidades de desarrollo: primero, los países desarrollados deberían proveer flexibilidades apropiadas a los países en desarrollo por razones de políticas de bienestar general y, segundo, autores y titulares de derechos deberían considerar las oportunidades que un adecuado sistema internacional podría proveerles también a ellos.

\section{Adoptar flexibilidades para avanzar enforcement.}

La mayor parte de los instrumentos internacionales sobre propiedad intelectual se han concentrado en armonizar la protección de los titulares de derechos a través de disposiciones sustantivas, estableciendo estándares mínimos de protección legal. El "Convenio de Berna", el "Acuerdo sobre los ADPIC", e inclusive los "Tratados Internet" de la OMPI han forzado cierto nivel de convergencia en diversos aspectos, tales como el rango de derechos exclusivos conferidos, requisitos de las limitaciones y excepciones a los derechos de autor, extensión del plazo de protección, entre otros. Sin embargo, la tutela efectiva de los derechos armonizados ha quedado reservado, esencialmente, al derecho interno de los países.

En los últimos años, los países desarrollados han enfatizado la necesidad de disponer de un régimen común para la tutela efectiva de la propiedad intelectual ${ }^{147}$. La Unión Europea ha armonizado un estándar comunitario para garantizar el cumplimiento de las normas de propiedad intelectual dentro de su mercado interno ${ }^{148}$. Los Estados Unidos también ha incluido

${ }^{147}$ Véase, e.g., "G8 Toyako Declaration on World Economy", 8 de julio de 2008, disponible en: http://www.america.gov/st/texttransenglish/2008/July/20080708102 050bpuh0.9821131.html (fecha de consulta: 15 de mayo de 2011).

${ }^{148}$ Directiva No 2004/48/CE del Parlamento Europeo y del Consejo de 29 de abril de 2004 relativa al respeto de los derechos de propiedad intelectual, Diario Oficial de la Unión Europea No L 195 de 02/06/2004, pp. 0016 - 0025. 
estándares similares en sus negociaciones bilaterales, particularmente en todos los acuerdos de libre comercio suscrito durante la década anterior ${ }^{149}$. Tanto la Unión Europea como los Estados Unidos, junto a otros países desarrollados, han negociado recientemente un instrumento internacional específicamente relativo la tutela de la propiedad intelectual, el denominado Anti-Counterfeiting Trade Agreement ${ }^{150}$. Estados Unidos está además negociando disposiciones similares en el Trans-Pacific Partnership, una iniciativa que intenta profundizar el libre comercio en la cuenca del Pacífi$\mathrm{co}^{151}$. Obtener el cumplimiento de las normas sobre propiedad intelectual es, por consiguiente, un asunto bien asentado en la agenda internacional de los países desarrollados.

Los países en desarrollo, en cambio, han expresado preocupaciones muy distintas. Por un lado, incrementar la observancia de las normas sobre propiedad intelectual parece contraproducente para sus comparativamente más débiles economías y, además, suscita preocupación por cómo ello condiciona las políticas públicas de los países y cuán consistente es con los derechos humanos. Por otro lado, estos países han levantado su propia agenda a efectos de obtener las flexibilidades que el derecho internacional vigente no les suministra, la denominada "Agenda para el Desarrollo". En este contexto, por ejemplo, diversas propuestas de tratados han sido introducidas ante la OMPI en materias tales como protección del conocimiento tradicional, acceso para personas con discapacidad, y excepciones a los derechos autorales para fines educacionales ${ }^{152}$. Los países en desarrollo han levantado su

${ }^{149}$ Los Estados Unidos ha incluido disposiciones similares en los tratados de libre comercio suscritos con Singapur, Chile, Marruecos, Australia, Costa Rica, El Salvador, Guatemala, Honduras, Nicaragua y República Dominicana, Bahrain, Omán, Perú, Colombia, Panamá, y Corea. Véase Free Trade Agreements, U.S. Trade Rep., http:// www.ustr.gov/tradeagreements/free-trade-agreements/free-trade-agreements (fecha de consulta: 15 de mayo de 2011).

150 "Acuerdo Comercial Anti-Falsificación" (versión no oficial en español, de 3 de diciembre de 2010). Disponible en: http://www.impi.gob.mx/work/sites/IMPI/resources/LocalContent/2361/32/Acuerdo_ACTA_3_Dic_2010_no_oficial_es.pdf (fecha de consulta: 13 de julio de 2011).

${ }^{151}$ Véase: Trans-Pacific Partnership, Intellectual Property Rights Chapter: Draft Feb. 10, 2011 (versión no oficial). Disponible en: http://keionline.org/sites/default/files/ tpp-10feb2011-us- text-ipr-chapter.pdf (fecha de consulta: 13 de julio de 2011).

${ }^{152}$ Véase: "Propuesta del Brasil, el Ecuador y el Paraguay en relación la limitaciones y excepciones: Propuesta de tratado de la Unión Mundial de Ciegos (UMC)", Documento OMPI, SCCR/18/5, 25 de mayo de 2009, disponible en www.wipo.int/ edocs/mdocs/copyright/es/sccr_18/sccr_18_5.doc (fecha de consulta: 13 de julio de 2011); y "Proyecto de tratado de la OMPI sobre excepciones y limitaciones para las personas con discapacidad, las instituciones docentes y de investigación, las bibliotecas y los archivos", Propuesta del Grupo Africano, Documento OMPI, SCCR/20/11, 15 
voz para expresar la actual insuficiencia de las flexibilidades provistas en los instrumentos internacional sobre propiedad intelectual para satisfacer sus necesidades propias.

Para los países desarrollados, obtener un adecuado nivel de tutela para la propiedad intelectual puede parecer razonable, pero no lo es para los países en desarrollo. Si los países desarrollados desean concesiones desde los países en desarrollo, es necesario trabajar en una agenda de compromiso que provea a los países en desarrollo suficientes flexibilidades para satisfacer apropiadamente sus necesidades. De otro modo, la regulación internacional de la propiedad intelectual acentuará las actuales inequidades, arriesgará seriamente su legitimidad, y excluirá a los países en desarrollo de cualquier la tutela efectiva. Ninguna agenda de tutela puede permear los países en desarrollo si los intereses de éstos no son apropiadamente abordados. En este contexto, adoptar flexibilidades en un instrumento internacional sobre derechos autorales debe ser parte de las negociaciones futuras, particularmente en caso de una nueva revisión de la ya cuarentona "Acta de París" del "Convenio de Berna".

\section{Proveer oportunidades para autores y titulares de derechos.}

Cada vez que los países en desarrollo han requerido flexibilidades en los foros internacionales, los titulares de derechos han expresado automáticamente su preocupación por la adopción de ellas. El meollo de su rechazo, incluso cuando han reconocido la urgencia de las necesidades de los países en desarrollo y su población, radica en que sería injusto hacer recaer sobre los hombros de los titulares de derechos el costo de la solución para tales países $^{153}$. Dichas flexibilidades son rechazadas no sólo por los titulares de derechos sobre obras potencialmente afectadas sino también por los titulares de derechos locales de los países en desarrollo, quienes ven la adopción de flexibilidades como una concesión de ventajas competitivas a los autores extranjeros, lo que, finalmente, podría minar la creatividad local. Sin embargo, estas preocupaciones sobredimensionan el potencial daño, y omiten completamente los beneficios de las flexibilidades para los propios autores y titulares de derechos.

La traducción de obras en otros idiomas no sólo provee acceso a las personas y oportunidades para el desarrollo de los países, sino que también abre mercados para los autores de las obras traducidas. Por ejemplo, un mecanismo adecuado de notificación puede permitir a los autores y titulares de

de junio de 2010, disponible en www.wipo.int/edocs/mdocs/copyright/es/sccr_20/ sccr_20_11.doc (fecha de consulta: 13 de julio de 2011).

${ }^{153}$ Lipszyc, Delia, cit. (n. 139), pp. 9 y 42; Mouchet, Carlos, cit. (n. 22), pp. 75-78. 
derechos estar en conocimiento de las oportunidades que sus obras tienen en mercados extranjeros y permitirles evaluar la conveniencia de entrar directamente en el mercado local en cuestión o dejar tal oportunidad para licenciatarios locales a través de una licencia voluntaria. Incluso si el titular de los derechos concernido no está en posición de controlar la traducción de la obra a un idioma extranjero, él todavía puede fiarse de editores locales, si éstos le garantizan una justa compensación. En otras palabras, la traducción de obras ofrece oportunidades a los autores y a los titulares de derechos autorales al transparentar el interés local en disponer de una obra, al facilitar la evaluación acerca de ingresar o no al mercado local, e incluso permitirles dejar los riesgos sobre los hombros de un intermediario.

\section{Figura 2:}

Principales países exportadores de libros, por su participación en el mercado, 2009.

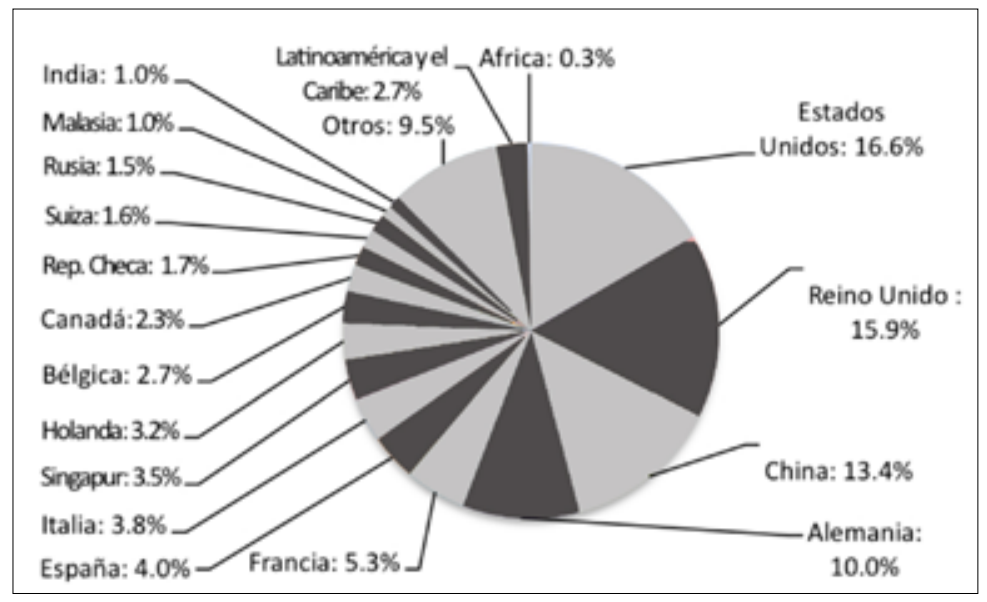

Fuente: Cerlalc, El Espacio Iberoamericano del Libro, 2010.

Un nuevo régimen de flexibilidades puede proveer oportunidades para los autores y titulares de derechos, pero diferentes tipos de oportunidades. Algunos países en desarrollo tienen mercado grandes, pero la mayor parte de ellos son reducidos, con pequeños y medianos editores, limitadas ediciones, y una demanda moderada. El actual mecanismo adoptado por el "Anexo" del "Convenio de Berna" parece desestimar las limitaciones que presentan los mercados de los países en desarrollo. La Figura 2 muestra el tamaño de mercado de los principales países exportadores de libros; en tal mercado, el conjunto de los países de Latinoamérica y el Caribe representan apenas un 2,7\% del total global, mientras que los países de África son sólo un 0,3\% de la oferta. Pero más todavía, hay significativas diferencias entre los mercados 
de los países en desarrollo; por ejemplo, el 77,7\% de la producción latinoamericana de libros se concentra en cuatro economías, tal como la Figura 3 muestra.

\section{FIgURA 3:}

Producción de títulos en Latinoamérica por país, 2009.

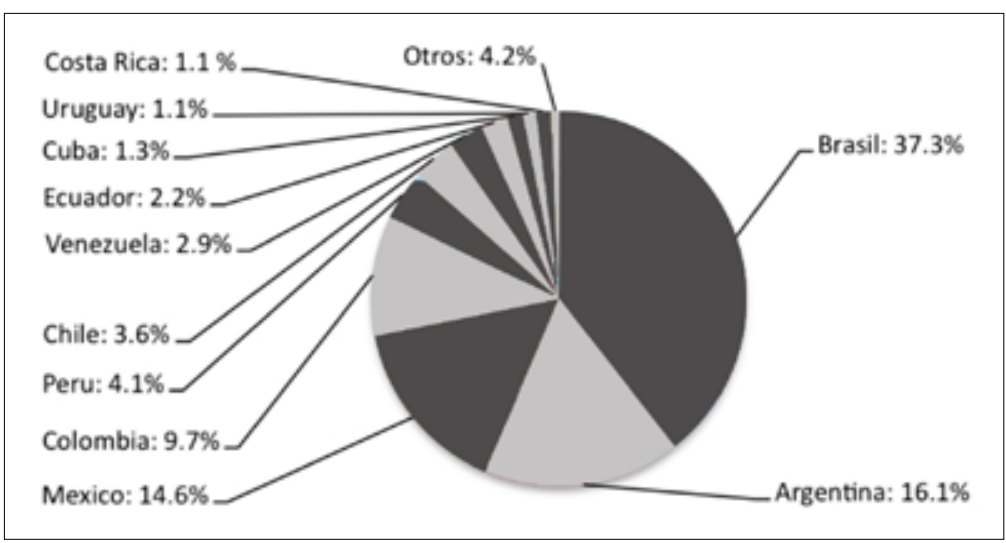

Fuente: Cerlalc, El Espacio Iberoamericano del Libro, 2010.

Para proveer oportunidades a los autores y titulares de derechos, un nuevo instrumento con flexibilidades necesita reconocer las limitaciones de los mercados de los países en desarrollo. Por ejemplo, como se ha mencionado, varios países de América Central tienen licencias obligatorias para traducción y reproducción, sin embargo ellos no las utilizan debido a la carencia de capacidades de los editores locales y el reducido tamaño de los mercados. En El Salvador, un país con menos de 6 millones de habitantes, apenas hay cinco compañías editoriales, de las cuales tres publican menos de 20 títulos al año ${ }^{154}$. En Chile, el tiraje promedio de libros es de 500 copias $^{155}$. Con tales capacidades y tamaños de mercado es extremadamente difícil sacar cualquier ventaja del "Anexo" porque los costos transaccionales son demasiado altos para ser asumidos por los editores locales de países en desarrollo.

A pesar de las limitaciones de los mercados de países en desarrollo, ellos aún ofrecen oportunidades para los autores y titulares de derechos.

\footnotetext{
${ }^{154}$ Centro Regional para el Fomento del Libro en América Latina, el Caribe, España y Portugal, CERLALC, cit. (n. 60), p. 75, según el cual, en 2009, un 68\% de los editores latinoamericanos publicaron menos de 20 libros al año, y sólo un 5\% publicó sobre 100 libros tal año.

${ }^{155}$ Cámara Chilena del Libro, International Standard Book Number, Informe Estadístico 2010 (Santiago de Chile, Cámara Chilena del Libro, 2011), pp. 35-36.
} 
Dos conceptos ayudan a explicar tales oportunidades: nicho de mercado y economías de escala.

Un nicho de mercado es una fracción del mercado formado por un reducido número de consumidores con necesidades similares y fácilmente identificables. Por ejemplo, lectores de mapudungun, el lenguaje usado principalmente en el Sur de Chile por alrededor de medio millón de población mapuche ${ }^{156}$; el tamaño de este específico mercado es extremadamente reducido si se lo compara con el tamaño usual de los mercados de países desarrollados. Precisamente por su reducido tamaño, el nicho de mercado es menospreciado por los grandes proveedores, lo cual permite que pequeños proveedores ofrezcan bienes y servicios específicamente diseñados para los consumidores de tal nicho de mercado. Autores y titulares de derechos que no pueden o no desean explotar un nicho de mercado por sí mismos pueden hacerlo a través de licenciatarios, ya sean voluntarios u obligatorios.

Además de la especificidad de la demanda y de la oferta, un nicho de mercado requiere ser suficientemente pequeño para ser subestimado por los grandes proveedores y, a la vez, suficientemente grande para resultar atractivo a los pequeños proveedores. Por ejemplo, el mercado argentino de alrededor de 100 mil lectores de guaraní puede ser extremadamente pequeño para resultar atractivo a la hora de traducir y reproducir obras para tales lectores. Sin embargo, si el número de personas que leen guaraní y potenciales consumidores creciese, la producción de libros traducidos para ellos podría resultas atractiva, pues el costo unitario de producción disminuiría si incrementásemos el número de unidades producidas - esto es, cuando la economía escala. Por ejemplo, si en adición a los lectores de guaraní argentinos fuese posible agregar aquellos del Brasil y Paraguay podríamos llegar a un mercado de alrededor 6 millones de potenciales lectores del guarani ${ }^{157}$, seguramente el mercado resultaría atractivo para algunos proveedores y, en consecuencia, para autores y titulares de derechos traducidos a tal idioma.

El mecanismo del "Anexo" debería reconocer los beneficios de las economías de escala resultantes de la agregación de demanda proveniente

${ }^{156}$ ZÚÑIga, Fernando, Mapudunguwelaymi am? ¿Acaso ya no hablas Mapudungun?': Acerca del estado actual de la lengua mapuche, en Estudios Públicos, 105 (2007), pp. 9-24.

${ }^{157}$ Paraguay presenta una situación singular en Latinoamérica, en que el idioma aborigen es predominante; con 6 millones de habitantes, donde el $90 \%$ son hablantes de guaraní, mientras sólo un $55 \%$ habla español. Debe ser dicho, además, que el guaraní es el principal idioma nativo empleado en el sector editorial en Latinoamérica; alrededor del 80\% de los libros publicados en idiomas nativos en la región entre los años 2005 y 2009 lo fueron en guaraní, llegando a 258 títulos. Centro Regional para el Fomento del Libro en América Latina, el Caribe, España y Portugal, Cerlalc, cit. (n. 60), pp. 62 y 66 . 
de diferentes países ${ }^{158}$. Desafortunadamente, no lo hace. Por un lado, la exportación de obras producidas al amparo del mecanismo previsto en el "Anexo" está prohibido ${ }^{159}$; hay algunas limitadas excepciones, pero sujetas a tal número de requisitos que ellas se tornan inoperables ${ }^{160}$. Por otro lado, a pesar de que la impresión en el exterior está permitida ${ }^{161}$, puede ser altamente dificultoso sortear las medidas en frontera con reproducciones hechas bajo licencia expedida por autoridades extranjeras. Las recientemente mencionadas limitaciones obstaculizan cualquier ventaja de las economías de escala entre países que comparten un idioma en común. Por ejemplo, Cabo Verde, un pequeño país africano con menos de medio millón de habitantes, como muchos otros pequeños países lusófonos ${ }^{162}$, no puede importar obras traducidas al portugués en Brasil, si una licencia obligatoria para traducción y reproducción fuese emitida ${ }^{163}$. Lo mismo puede ser dicho de la comunidad hispanohablante de Latinoamérica, francófonos de África, y árabe del Medio Oriente.

Algunas voces de los países en desarrollo han rechazado mecanismos similares a aquél adoptado por el "Anexo" sobre la base de que ellos socavarían los intereses de los autores locales forzándoles a competir con los autores

${ }^{158}$ Véase Fometeu, Joseph, cit. (n. 58), p. 43, quien sugiere que las exportaciones sean a lo menos permitidas entre países con similar grado de desarrollo que no disponen de acceso a la obra original y se han habilitado de acuerdo a las normas establecidas por el Anexo.

${ }^{159}$ Artículo IV (4) (a) del "Anexo" del "Convenio de Berna”.

${ }^{160}$ Artículo IV (4) (c) del "Anexo" del "Convenio de Berna”.

${ }^{161}$ Artículos IV (4) (a) y IV (5) del “Anexo” del “Convenio de Berna”. Véase Lipszyc, Delia, cit. (n. 139), pp. 17-26; Fernay, Roger, Paris 1971, ou les aventures d'un 'package deal', en Revue Internationale du Droit d'Auteur, 70 (Oct. de 1971), pp. 3233; Fometeu, Joseph, cit. (n. 58), p. 25; Ulmer, Eugen, cit. (n. 24), pp. 357-359, y 362. Véanse también: General Report of Paris Conference, en UNESCO, cit. (n. 32), párrafo 40; World Intellectual Property Organization, cit. (n. 14), p. 168. En contra Ficsor, Mihály, cit. (n. 141), p. 11.

${ }^{162}$ De hecho, cuatro de los ocho países en que el portugués es lengua oficial no son parte del Convenio de Berna: Angola, Mozambique, Santo Tomé y Príncipe, y Timor Oriental.

${ }^{163}$ Brasil no dispone de un sistema de licencias obligatorias para la traducción y/o reproducción de obras en idiomas extranjeros al portugués ni a ningún idioma nativo. Véase: Paranaguá, Pedro, Excepciones y limitaciones al derecho de autor en Brasil: logrando un equilibio entre la protección y el acceso al conocimiento, en CERDA SILVA, Alberto (editor), Acceso a la cultura y derechos de autor (Santiago de Chile, ONG Derechos Digitales, 2008), pp. 63-64; y, Mizukami, Pedro y otros, Exceptions and Limitations to Copyright in Brazil: A Call for Reform, en Shaver, Lea (editora), Access to Knowledge in Brazil: New Research on Intellectual Property, Innovation and Development, (Londres, Bloomsbury, 2010), pp. 48-54. 
extranjeros en términos desfavorables ${ }^{164}$. Este argumento es errado, sino engañoso, porque está basado en la suposición de que las obras disponibles bajo un licencia obligatoria no generan pago alguno a los titulares de derechos; en cambio, muy por el contrario, dichas obras deben pagar compensación a ellos. De hecho, el "Anexo" de la "Convenio de Berna" exige el pago de una compensación de acuerdo a "la escala de cánones que normalmente se abonen en los casos de licencias libremente negociadas entre los interesados en los dos paises de que se trate" ${ }^{165}$. El cálculo de la compensación de acuerdo a la fórmula establecida por el "Anexo" es sumamente restrictivo porque el promedio de las tasas usuales en los países desarrollados incrementa su monto y, consiguientemente, eleva el costo de acceso de los países en desarrollo; además, al imponer tasas más altas que las usuales en los mercados de países en desarrollo se socava el acceso necesario para una amplia diseminación del conocimiento, obligando finalmente a dichos países a desistir de acceder a un determinado contenido. Debe decirse, en cambio, que la adopción de una tasa conforme lo usual en el mercado de los países en desarrollo no dañaría los intereses de los autores y titulares de derechos, ya que se trata de ingresos que éstos actualmente no perciben por la falta de explotación de sus obras en dichos mercados. Esta fórmula tampoco dañaría a los titulares de derechos locales, quienes competirían en igualdad de condiciones con los foráneos, en cuanto al monto pagado por derechos autorales.

Los detractores de las flexibilidades para los países en desarrollo podrían argumentar que facilitar la traducción y reproducción de las obras puede destruir un mercado emergente, particularmente para los principales idiomas coloniales: español, francés, e inglés. Desafortunadamente, no hay datos disponibles acerca del tamaño y funcionamiento real de estos mercados. Sin embargo, es justo decir que los principales países exportadores de libros también sean principales traductores de ellos. Tal como muestra la Figura 2, Estados Unidos controla más del $16 \%$ de las exportaciones ${ }^{166}$, pero menos del 3\% de su producción total corresponde a traducciones ${ }^{167}$; de hecho, de acuerdo a data recolectada por la Universidad de Rochester, en 2010 sólo 317 libros traducidos al inglés fueron publicados, de los cuales 48 correspondían a libros originalmente escritos en español ${ }^{168}$. El Reino Unido, que es el segundo

${ }^{164}$ Lipszyc, Delia, cit. (n. 139), p. 44.

${ }^{165}$ Artículo IV.6 a) (i) del "Anexo" del "Convenio de Berna”.

${ }^{166}$ Centro Regional para el Fomento del Libro en América Latina, el Caribe, España y Portugal, Cerlalc, cit. (n. 60), p. 172.

${ }^{167}$ University of Rochester, “Translation Database”, disponible en: http://www. rochester.edu/College/translation/threepercent/index.php?s=database (fecha de consulta: 15 de mayo de 2011).

${ }^{168} \mathrm{El} 2008$, 362 libros traducidos al inglés fueron publicados en Estados Unidos, 
principal exportador de libros con un $15,9 \%$ del mercado ${ }^{169}$, publicó sólo 93 libros traducidos desde el español en $2007^{170}$. Estos números sugieren que, incluso en el caso de las principales lenguas coloniales en mercados que disfrutan de los beneficios de las economías a escala, las licencias voluntarias para traducción son aún limitadas y el régimen legal internacional vigente ciertamente no facilita la traducción desde un idioma a otro.

La información disponible de países latinoamericanos muestra que el número de traducciones es aún reducido y se concentra en obras originalmente escritas en inglés. En 2008, de 46.993 libros publicados en Brasil 6.626 eran traducciones al portugués, de las cuales un $60,1 \%$ lo eran desde el inglés ${ }^{171}$. El mismo año, de los 6.469 libros publicados en México sólo 164 eran traducciones al español, un $66,0 \%$ de las cuales provenían de obras originalmente escritas en inglés ${ }^{172}$. Igualmente, en 2010 , los editores chilenos publicaron 5.107 libros, de los cuales 302 eran traducciones al español, y el inglés era la principal lengua de origen $(77,5 \%)^{173}$. Los altos números de Brasil pueden explicarse por el relativamente reducido número de países que hablan portugués, lo cual reduce las oportunidades para satisfacer la demanda con oferta desde el extranjero y obliga a la traducción local. El hecho de que el inglés sea el principal idioma desde el cual se verifican las traducciones en el sector editorial latinoamericano ha sido explicado como un efecto de su amplio uso en comunicaciones técnicas y comerciales ${ }^{174}$.

La deprivación de libros en países en desarrollo, particularmente cuando ellos no están disponibles en un idioma local, no sólo afecta el acceso de los usuarios y las necesidades de esos países, sino que también priva a los autores y titulares de derechos de la oportunidad para explotar sus obras, abrir merca-

de ellos 48 fueron traducidos desde el español; el 2009, 357 fueron las traducciones y 62 de ellas eran libros originalmente escritos en español. Véase: University of RoCHESTER, cit. (n. 167).

${ }^{169}$ Centro Regional para el Fomento del Libro en América Latina, el Caribe, España y Portugal, Cerlalc, cit. (n. 60), p. 101.

${ }^{170}$ Ministerio de Industria, Turismo y Comercio de España. Las traducciones de libros del español al inglés en Reino Unido aumentan un 50\% en tres años, (12/05/2007), disponible en http://www.icex.es/icex/cda/controller/pageICEX/0,6558,5518394_5 519005_5604470_4036437,00.html (fecha de consulta: 1 de mayo de 2011).

${ }^{171}$ Centro Regional para el Fomento del Libro en América Latina, el Caribe, España y Portugal, Cerlalc, cit. (n. 60), pp. 43 y 84.

${ }^{172}$ Ibíd.

${ }^{173}$ Cámara Chilena del Libro, cit. (n. 155), pp. 12 y 30.

${ }^{174}$ Centro Regional para el Fomento del Libro en América Latina, el Caribe, España y Portugal, Cerlalc, cit. (n. 60), p. 99, consignando un estudio realizado el 2010 por "Index Translationum" que estableció que el inglés es el idioma de origen predominante en las traducciones, con un 55\% de ellas. 
dos, y hacer negocios. Un nuevo instrumento que brinde flexibilidades para satisfacer necesidades de desarrollo necesita adoptar mecanismos para prevenir tal privación, particularmente permitiendo el apropiado funcionamiento de nichos de mercado y economías de escala en los países en desarrollo.

\section{EL DISEÑO DE UN NUEVO INSTRUMENTO PARA}

\section{SATISFACER LAS NECESIDADES DE DESARROLLO}

El "Anexo" del "Convenio de Berna" tenía por propósito satisfacer las necesidades de los países en desarrollo a efectos de proveerles acceso a obras protegidas y, en consecuencia, permitirles su desarrollo. Desafortunadamente, el "Anexo" fracasó ${ }^{175}$. Si bien los expertos tienden a estar de acuerdo en torno a la ineficacia de las disposiciones del "Anexo", no existe acuerdo respecto a cómo superar tal fracaso. Algunos de ellos han expresado escepticismo de que el Convenio pueda ser cambiado a efectos de satisfacer las necesidades de los países en desarrollo, y han sugerido que la solución debe ser encontrada en otro foro $u$ otro instrumento internacional ${ }^{176}$. Otros expertos, en cambio, se inclinan por modificar el Convenio a tales efectos ${ }^{177}$. Este artículo sugiere un bosquejo de los temas que deben ser incluidos en un nuevo instrumento a efectos de disponer de las adecuadas flexibilidades para satisfacer necesidades de desarrollo en un instrumento internacional sobre derechos autorales.

Esta sección propone un nuevo instrumento para satisfacer las necesidades de los países en desarrollo sobre a base del actual mecanismo previsto en el "Anexo" del "Convenio de Berna". Así, se sugiere extender el ámbito de aplicación de las disposiciones, diversificar los mecanismos legales que brindan flexibilidad, reducir y simplificar sus burocráticos trámites, abrazar las oportunidades que brindan las nuevas tecnologías, permitir la exportación

\footnotetext{
${ }^{175}$ Algunos autores sugieren condescendientemente que el "Anexo" habría favorecido la negociación directa en el sector editorial, incrementando las licencias voluntarias. Véanse: Ricketson, Sam, cit. (n. 22); y, World Intellectual Property Organization, WIPO Intellectual Property Handbook: Policy, Law and Use (Ginebra, WIPO, 2004), p. 268, párrafo 5.204. En cambio, otros han rechazado tal aseveración y, en cambio, sostienen que los países en desarrollo parecen atrapados en las complejas y burocráticas reglas del Anexo, al extremo de hacer dudar de la propia existencia de tales licencias. Véase: Ficsor, Mihály, cit. (n. 141), pp. 10-11.

${ }^{176}$ Véanse, e.g.: STORY, Alan, Burn Berne: Why the Leading International Copyright Convention Must Be Repealed, en Houston Law Review, 40 (2003) 3, pp. 763-801; Story, Alan, An Alternative Primer on National and International Copyright Law in the Global South: Eighteen Questions and Answers (Reino Unido, CopySouth Research Group, 2009); y Drahos - Braithwaite, cit. (n. 10), p. 78.

${ }^{177}$ Véase, e.g.: CHON, Margaret, cit. (n. 81), pp. 218-249.
} 
de obras producidas al amparo del nuevo instrumento, mejorar el rol de la organización internacional competente en la materia, y, finalmente, se hacen algunas consideraciones en torno a la elección del foro internacional en que la propuesta debería de avanzar.

\section{Expandiendo el ámbito de aplicación.}

Las necesidades de desarrollo no son exclusivas de países no desarrollados y el "Anexo" comete un error cuando limita su ámbito de aplicación sólo a los países en desarrollo. Los desafíos para el desarrollo no están asociados únicamente a estos países y sus habitantes; otras comunidades desaventajadas también necesitan de especiales flexibilidades en materia de derechos de autor, incluso en países desarrollados, tales como minorías políticas, filosóficas, sexuales, pero especialmente minorías lingüísticas.

Un nuevo instrumento debe adoptar una aproximación más holística al desarrollo, reconociendo que sus desafíos no se refieren únicamente a países en desarrollo, sino que a comunidades. Consecuentemente, es un error limitar las flexibilidades del derecho de autor a una serie de países; ellas deberían estar también disponibles para cualquier comunidad que sufre desventajas que impiden la plena realización de las potencialidades de sus miembros. Esto no es algo nuevo en la regulación internacional de la propiedad intelectual; de hecho, este asunto también se suscitó durante la discusión de un mecanismo que permitiese a los países que carecían de capacidades de manufactura emitir una licencia obligatoria respecto de productos farmacéuticos; este proceso concluyó reconociendo que dichas capacidades son esencialmente relativas, y el "Acuerdo sobre los ADPIC" permitió el potencial uso de tales licencias por cualquier país, ya sea que fuese desarrollado o en desarrollo ${ }^{178}$. Hasta cierto punto, este es también el caso de la mencionada cláusula del "régimen de diez años" prevista en el "Convenio de Berna", la cual permite sustituir el derecho exclusivo de traducción por la extinción del derecho de autor si la obra no está disponible en un idioma de general uso en el mencionado país dentro de los diez años siguientes al de su primera publicación; desafortunadamente, como se ha mencionado, este régimen es prácticamente inútil debido a sus severas limitaciones ${ }^{179}$.

Podría sostenerse que los desafíos de una comunidad en particular

${ }^{178}$ Véase la Decisión del Consejo General de 30 de agosto de 2003, sobre Aplicación del párrafo 6 de la Declaración de Doha relativa al acuerdo sobre los ADPIC y la salud pública. WT/L/540 y Corr.1. Véase tambièn: CorreA, Carlos, Implications of the Doha Declaration on the Trips Agreement and Public Health, in Health Economics and Drugs Series No 012 (Ginebra, Organización Mundial de la Salud, OMS, 2002), p. 23.

${ }^{179}$ Véase más arriba notas 13 a 16 y su texto principal. 
dentro de un país deben ser resueltos a través de derecho interno antes que apelando a instrumentos internacionales. Esto puede ser verdad en ciertos casos, tal como China hizo al permitir la traducción desde el idioma dominante a cualquier otro idioma de una minoría lingüística dentro del país. Sin embargo, las soluciones en derecho interno tienen un ámbito de aplicación meramente local; en el caso chino, el mecanismo se limita a obras de autoría china porque el "Anexo" protege a los autores extranjeros. Si China desease extender su política pro-acceso a obras de autoría extranjera y, a su vez, estar en regla con sus compromisos internacionales, le resultaría muy difícil hacerlo a través del "Anexo" o invocando simples excepciones a los derechos autorales. Además, el mecanismo ofrecido por el "Anexo" se limita a países en desarrollo, como China, pero no favorece el desarrollo de minorías lingüísticas en países desarrollados.

$\mathrm{Al}$ adoptar una solución que satisfaga necesidades de desarrollo, particularmente de minorías oprimidas, es necesario considerar no sólo que el gobierno pueda expedir licencias obligatorias. Es necesario disponer de un mecanismo que permita a los miembros de aquellas comunidades superar las limitaciones o negligencias de sus gobiernos y solicitar directamente tal licencia de un organismo internacional, tal como la Secretaría de la OMPI o de la UNESCO. Actualmente, es usual encontrar mecanismos que permiten la comparecencia directa de los nacionales de un estado ante un organismo internacional, tal como la Comisión Interamericana de Derechos Humanos, la UNESCO, e inclusive la propia OMPI.

En suma, un nuevo instrumento que provea flexibilidades para fines de desarrollo no debe limitarse a los países en desarrollo, sino que debe hacerse extensivo a comunidades y debería proveer mecanismos para que éstas puedan obtener licencias obligatorias no sólo de sus respectivos gobiernos, sino también de algún organismo internacional, en caso de negligencia de sus gobiernos.

\section{Diversificando los mecanismos disponibles.}

El "Anexo" del "Convenio de Berna" establece un sistema de licencias obligatorias para la traducción y reproducción de obras protegidas por los derechos de autor básicamente a efectos de satisfacer propósitos de educación e investigación ${ }^{180}$, y enfatizando en un caso que el uso debe ser sin ánimo de lucro ${ }^{181}$. Este sistema de licencias no autoriza ningún uso gratuito; en vez de ello, este autoriza usos obligatorios con el pago de una justa compensación

\footnotetext{
${ }^{180}$ Artículos II (5) y III (7) b) del “Anexo” del Convenio de Berna.

${ }^{181}$ Ibíd., artículo II (9) a) iv)
} 
al titular de los derechos ${ }^{182}$. Nuevamente, el "Anexo" reduce el ámbito de aplicación e impacto efectivo del mecanismo previsto en él, ya que no autoriza la explotación con ánimo de lucro de las obras, a pesar de que el licenciatario debe pagar una compensación al titular de los derechos autorales.

Una licencia obligatoria puede ser una solución razonable para usos comerciales y con ánimo de lucro de obras protegidas por derechos de autor, pero el "Anexo" no permite este tipo de usos, sino que, en cambio, adopta una tortuosa solución para lo que son esencialmente traducciones y reproducciones de obras sin ánimo de lucro. Esto crea el absurdo de que algunos países en vez de implementar la solución provista por el "Anexo" han adoptado excepciones y limitaciones a los derechos de autor sujetas a los requisitos de la "prueba de los tres pasos"183. De hecho, esto crea la paradojal situación de que algunos países en desarrollo tienen peores condiciones de acceso a las obras protegidas que las disponibles en países desarrollados ${ }^{184}$. Además, al mismo tiempo, la solución ofrecida por el "Anexo" ha producido el efecto no deseado que la mayor parte de los países en desarrollo se han restringido a sí mismos de adoptar una solución basada en excepciones o limitaciones a los derechos de autor.

Un nuevo intento por proveer flexibilidades para la traducción y reproducción de obras para fines de desarrollo debe hacer una razonable distinción entre usos con y sin ánimo de lucro. Por ejemplo, limitando las licencias obligatorias (e.g. autorizaciones bajo compensación) para la traducción y reproducción con fines comerciales, y adoptando excepciones y limitaciones (i.e., autorizaciones gratuitas) para traducciones y reproducciones con fines personales, para efectos de educación e investigación, y otros fines no comerciales. Asumir el costo de licenciamiento es justo para iniciativas de orden comercial, pero abruma aquellas iniciativas sin ánimo de lucro, y el "Anexo" debe reconocer la diferencia entre tales usos, aun cuando tal distinción pueda parecer difusa en situaciones límites.

Se ha dicho que las licencias obligatorias no son un mecanismo eficiente, porque ellas tienden a su estancamiento, menoscabando las necesarias flexibilidades de todo régimen jurídico. Esto puede ser verdad, pero sólo en parte. La traumática experiencia de los Estados Unidos con la sempiterna licencia obligatoria para reproducción mecánica es probablemente el paradigma de tal argumento ${ }^{185}$. Sin embargo, en el derecho comparado es posible encontrar

\footnotetext{
${ }^{182}$ Ibíd., artículo IV.6 a)

${ }^{183}$ Véanse, más arriba, las nota 83 a 91 y su texto principal.

${ }^{184}$ Véase, e.g.: CHON, Margaret, cit. (n. 81), pp. 218-249.

${ }^{185}$ Véase: Merges, Robert P., Contracting into Liability Rules: Intellectual Property Rights and Collective Rights Organizations, en California Law Review, 84 (1996) 5, pp. 1308-1316.
} 
regímenes de licencia obligatorias muchísimo más flexibles, tanto en sus procedimientos como en sus sistema de tarificación ${ }^{186}$. En consecuencia, preservar un mecanismo de licencia obligatoria para ciertos casos no significa adoptar un mecanismo inflexible e incapaz de adaptarse a nuevos desafíos.

En adición al sistema de excepciones y licencias obligatorias, es recomendable introducir alguna flexibilidad en el mecanismo provisto por el "régimen de diez años". Este permitiría sustituir el derecho exclusivo de traducción por la extinción de tal derecho si la obra no está disponible en un idioma hablado en un determinado país. Sobre este punto es posible brindar efectividad a dicho mecanismo reduciendo el plazo dentro del cual una obra debe estar disponible en el idioma en cuestión, permitiendo su adopción por cualquier país en desarrollo, ya sea al acceder al "Convenio de Berna" o con posterioridad; garantizando la compatibilidad de este mecanismo con aquél previsto en el de licencias obligatorias previsto en el "Anexo", y proscribiendo la retaliación en contra de los autores nacionales de un país de origen que ha implementado este régimen en su derecho interno. Estas modificaciones pueden mitigar en parte las necesidades de los países en desarrollo permitiéndoles una amplia diseminación de obras para efectos de educación, estudios e investigación.

\section{Proveyendo una inequivoca solución para entornos en línea.}

El "Anexo" parece, cuando menos, ambiguo en cuanto a su aplicabilidad al entorno en línea. Mientras el "Convenio de Berna” provee un estándar para evaluar la adopción de excepciones y limitaciones a los derechos autorales en el contexto de las nuevas tecnologías, el "Anexo" provee controvertidas normas para que los países en desarrollo puedan sacar partido de las oportunidades que ofrecen las nuevas tecnologías. En vez de ello, el mito de Internet como la perfecta máquina de hacer copias sin fronteras ha invadido la literatura jurídica, predisponiendo negativamente a la concesión de flexibilidades para el uso de obras en línea.

A diferencia de cuanto acontecía a comienzos de la era de las redes digitales, la Internet de hoy es un espacio susceptible de regulación como cualquier entorno análogo. A las disposiciones legales y las cláusulas contractuales, se suma un creciente número de medidas tecnológicas que contribuyen a controlar y disciplinar en comportamiento de los usuarios de la Internet. Es tecnológicamente posible controlar el acceso, uso, y copia de los contenidos; es también posible discriminar sobre la base de elementos geográficos para efectos de ajustar la experiencia en línea al marco jurídico local; y, cierta- 
mente, el anonimato no es más la regla por defecto de las comunicaciones en línea ${ }^{187}$.

Adicionalmente a la experiencia de sistemas de localización geográfica como los empleados por iTunes, Yahoo! y Google, puede ser sumamente útil recoger la experiencia de iniciativas que proveen acceso público a contenidos protegidos por derechos autorales. A efectos de cumplir con las restricciones de los derechos de autor, dichas iniciativas han debido adoptar sofisticados modelos de operaciones. Por ejemplo, Open Library es un proyecto que gestiona condiciones especiales de licenciamiento con los editores a través de las cuales se permite poner libros a disposición de los usuarios en línea. Lo que es interesante acerca de este proyecto es que los libros electrónicos se comportan exactamente como libros análogos: ellos pueden ser prestados al público por un determinado período de tiempo, pero no varias copias a la vez sino que uno a uno. Los usuarios deben acudir a una biblioteca participante del proyecto u otros lugares que disponen de números de conexión IP previamente acreditados ${ }^{188}$, para bajar allí los libros en sus dispositivos de lectura (computador o lector de libros electrónicos) por un período de tiempo, después del cual los libros se desactivan a través de un dispositivo tecnológico. Actualmente, Open Library opera en varias bibliotecas públicas y universitarias de los Estados Unidos, así como en Canadá y recientemente también en Guatemala. El proyecto de Open Library sugiere que, con un adecuado soporte tecnológico y legal, los países y comunidades en desarrollo pueden proveer a su población un más amplio acceso a contenidos protegidos por derechos de autor.

Sin embargo, el marco legal internacional es algo evasivo al proveer un mecanismo que permita a los países en desarrollo el uso de entornos digitales como plataformas de acceso a contenidos protegidos. Si licencias voluntarias no son extendidas, el "Anexo" del "Convenio de Berna" parece insuficiente para satisfacer las necesidades de desarrollo. Un nuevo instrumento debe clarificar inequívocamente su aplicación a entornos en línea ${ }^{189}$, permitiendo la reproducción digital y el acceso en línea, estableciendo disposiciones sobre limitaciones y condiciones de tal acceso, precisando es estatus de los servicios de traducción automática en línea, y regulando las medidas de protección

${ }^{187}$ Gold Smith, Jack - Wu, Tim, Who Controls the Internet: Illusions of a Borderless World (Nueva York, Oxford University Press, 2008), pp. 49-63.

${ }^{188}$ Cada vez que un usuario se conecta a Internet, la compañía prestadora de servicios de acceso le provee un número IP ("Internet Protocol number"). Este número puede ser permanente o dinámico, según si está asociado a un determinado computador o varia con cada conexión.

${ }^{189}$ Véanse, más arriba, las notas 127 a 146 y su texto principal. 
tecnológicas que controlan el acceso y uso de los contenidos protegidos por derechos de autor.

Obtener una inequívoca solución respecto de las flexibilidades en relación al uso de las obras en entornos en línea puede requerir reconocer los riesgos del uso inapropiado de las tecnologías. En consecuencia, los países en desarrollo deberían implementar una regulación que previniese el uso ilegal de obras protegidas por el derecho de autor. Negar el acceso en algunos casos puede ser justo si, en cambio, tal acceso es apropiadamente provisto en otros casos; en este sentido, un nuevo mecanismo debe balancear los intereses competitivos de autores, titulares de derechos, usuarios, y comunidades. Al crear tal balance, el precio que los países en desarrollo pueden estar obligados a pagar es proveer protección y enforcement en casos de uso ilegal de obras protegidas por derechos de autor.

\section{Simplificación de los trámites y requisitos.}

El "Anexo" del "Convenio de Berna" establece un extremadamente burocrático sistema de licencias obligatorias en favor de los países en desarrollo; tal sistema no se extiende a las limitaciones y excepciones al derecho de autor que siguen reglas diferentes. Tal burocracia se basa en la sospecha de que los países en desarrollo abusarían o malemplearían las flexibilidades. Para prevenir tal teórico abuso, el "Anexo" ha adoptado varias restricciones que aplican tanto en el derecho internacional como en el derecho doméstico de los países en desarrollo. Esto genera una superposición de requisitos que hace del "Anexo" un mecanismo laberíntico y complicado, lleno de distinciones entre categorías de obras, términos, e idiomas, entre otros. Con toda razón, algún autor ha calificado el sistema como impracticable ${ }^{190}$.

A nivel internacional, un país en desarrollo que desea disfrutar de las disposiciones del "Anexo" no sólo debe habilitarse a sí mismo mediante notificación al director general de la OMPI, sino que además debe renovar tal notificación periódicamente ${ }^{191}$. Esto crea incertidumbre para quienes desean obtener una licencia, de acuerdo a su legislación interna, cuando los países no han cumplido con el proceso de notificación a nivel internacional ${ }^{192}$. Este

${ }^{190}$ CHOn, Margaret, Intellectual Property "from Below": Copyright and Capability for Education, en University of California Davis Law Review, 40 (2007), pp. 803-854; Véanse: Ndiaye, Ndéné, cit. (n. 22); OKedij, Ruth L., The International Copyright System: Limitations, Exceptions and Public Interest Considerations for Developing Countries in the Digital Environment (Ginebra, International Centre for Trade and Sustainable Development - ICTSD, 2005), pp. 25 -26. En contra, Ricketson - GinsbURG, cit. (n. 22), párrafos 14.103-14107.

${ }^{191}$ Artículos I (1) y I (2) del "Anexo" del "Convenio de Berna”.

${ }^{192}$ Véase más arriba la nota 74 y su texto principal. 
es, por ejemplo, el caso de los editores de los países latinoamericanos que han implementado el mecanismo previsto en el "Anexo", pero cuyos gobiernos han omitido habilitarse mediante notificación a la OMPI.

A nivel nacional, los países deben implementar las disposiciones del "Anexo" en su derecho interno, teniendo el cuidado de adoptar un sistema complejo de reglas relativas a categorías de obras, idiomas, plazos, calidad de las traducciones, y otros varios requisitos. Los potenciales licenciatarios tienen que manejar esa confusa regulación. Además, es necesario crear un procedimiento para permitir la comparecencia de los interesados ante la autoridad judicial o administrativa competente, la cual generalmente carece de experiencia en la materia.

En general, tales requisitos desincentivan el uso del mecanismo por los editores locales de países en desarrollo, porque ellos agregan un nuevo y significativo costo al proceso editorial, en adición a la remuneración de los traductores y a la compensación para los titulares de derechos. En el pequeño mercado de los países en desarrollo, la suma de los costos de los procedimientos establecidos por el "Anexo" para obtener una licencia obligatoria incrementan considerablemente el costo final de una iniciativa editorial. En otros términos, los costos transaccionales hacen el sistema inviable.

Un nuevo instrumento internacional debe simplificar el mecanismo provisto a los países en desarrollo a través de la adopción de varias medidas. La tramitación burocrática e innecesaria debe ser eliminada, tal como la notificación y su periódica renovación al director general de la OMPI; en cambio, el mecanismo podría adoptar un procedimiento más simple de notificación, como aquél previsto para licencias obligatorias en el "Acuerdo sobre los ADPIC” 193 . Otras mejoras pueden incluir la estandarización de las reglas, particularmente respecto a plazos y categorías de obras, y la remoción de las medidas de proteccionismo a idiomas coloniales ${ }^{194}$.

La tecnología también puede ayudar a la introducción de mejoras al sistema. Como ya se ha mencionado, el "Anexo" debe clarificar su aplicación al entorno en línea. Aquí, en cambio, el propósito es enfatizar que el nuevo instrumento debe incorporar el uso de las tecnologías para facilitar su aplicación, gestión administrativa, y emisión de licencias, quizá creando un sistema de información comprensivo, abierto, y en línea, similar a aquél disponible para el sistema de nombres de dominio: el "Protocolo de Internet Whois", que permite identificar y en ocasiones contactar al asignatario de un nombre de dominio. Tal sistema de información podría introducir significativas mejoras, permitiendo la búsqueda pública y global de los autores y titulares de

${ }^{193}$ Véase más arriba la nota 178 y su texto principal.

${ }^{194}$ Véase Fometeu, Joseph, cit. (n. 58), p. 43. 
derechos sobre obras susceptibles de licenciamiento, coordinando la acción de las autoridades locales competentes, facilitando las comunicaciones entre potenciales licenciatarios y licenciadores, e introduciendo transparencia en relación al funcionamiento del sistema, algo de que el actual sistema del "Anexo" carece por completo.

\section{Permiso para la exportación de obras.}

La prohibición sobre las exportaciones es una medida excesivamente estricta prevista en el "Anexo" del "Convenio de Berna". Establecida con el propósito de prevenir que las obras producidas al amparo de una licencias obligatoria inundasen los mercados de otros países, la prohibición, en cambio, ha socavado cualquier uso del mecanismo por aquellos países que carecen de capacidades de manufactura o cuyas economías son tan pequeñas que hacen sumamente costoso hacer uso del mecanismo. Es verdad que el "Anexo" permite la impresión en el extranjero ${ }^{195}$, pero ello tampoco sirve si el potencial mercado del país que emitió la licencia es reducido. También es verdad que el "Anexo" prevé algunas excepciones que permiten la exportación de obras de un país a otro ${ }^{196}$, pero ellas son extremadamente limitadas y sus requisitos tan burocráticos que han hecho de tales excepciones verdadera letra muerta ${ }^{197}$.

Un nuevo mecanismo para el desarrollo debe reconocer las ventajas de las economías de escala, particularmente para países en desarrollo, y, consiguientemente, permitir la exportación de obras producidas al amparo de una licencia obligatoria. Algunos autores han sostenido la necesidad de permitir exportaciones, pero limitadas a países en análogo estado de desarrollo debidamente habilitados ${ }^{198}$. Sin embargo, si el nuevo mecanismo tiene el propósito de satisfacer necesidades de desarrollo en vez de sólo necesidades de países en desarrollo, él debe permitir la exportación también a países desarrollados, cuando los bienes tienen por propósito satisfacer las necesidades de comunidades desaventajadas, tales como habitantes de los Estados Unidos hablantes de amhárico o mapudungun. Además, requerir licenciamiento del país importador cuando la obra ya está disponible crea innecesaria burocracia, redundancia de esfuerzos, y barreras artificiales para el libro flujo de bienes y servicios.

Adicionalmente a permitir las exportaciones de obras producidas al amparo de una licencia obligatoria, el nuevo mecanismo debe remover los obstáculos para el libre flujo de dichas obras. Tradicionalmente, las auto-

\footnotetext{
${ }^{195}$ Véase más arriba la nota 161.

${ }^{196}$ Artículo IV (4) (a) del "Anexo" del "Convenio de Berna”.

${ }^{197}$ Ibíd., artículo IV (4) (c).

${ }^{198}$ Fometeu, Joseph, cit. (n. 58), p. 43.
} 
ridades aduaneras han tenido el poder de limitar la circulación de bienes que infringen las normas sobre propiedad intelectual en el país exportador e importador, pero no en aquéllos casos en que las mercaderías están en tránsito. En los últimos años, sin embargo, es posible constatar la extensión de la competencia de las autoridades aduaneras para adoptar medidas en frontera también en contra de bienes en tránsito ${ }^{199}$. Si la exportación de obras bajo un nuevo instrumento es permitida, no debería permitirse las medidas en frontera en contra de legítimas exportaciones de acuerdo a la legislación de los países exportador e importador; los servicios aduaneros deberían abstenerse de retener obras en tránsito porque ellas no cumplen con su legislación interna sobre derechos de autor, si ellas cumplen con la legislación de los países exportador e importador.

\section{Mejora del apoyo institucional.}

La organización internacional competente en materia de derechos de autor debe jugar un rol más relevante en la implementación de una solución para los países en desarrollo y comunidades desaventajadas a efectos de permitir una amplia diseminación del conocimiento. Desafortunadamente, bajo la vigencia del "Anexo" del "Convenio de Berna", la OMPI ha jugado un papel menor, a pesar de las expectativas que generó a comienzos de los setenta ${ }^{200}$. El simple hecho de que el mecanismo previsto en el "Anexo" es aún incomprendido por sus beneficiarios y que no exista siquiera un estudio crítico de sus disposiciones es suficientemente expresivo del precario involucramiento que la OMPI ha tenido. Para aquéllos que hamos tenido la oportunidad de participar de los programas de capacitación de la OMPI, la ausencia de asistencia técnica en materia de flexibilidades para países en desarrollo es desconcertante ${ }^{201}$.

Un mecanismo apropiadamente diseñado, a diferencia del actualmente existente en el "Anexo", debe prever un rol de apoyo institucional. El organismo internacional pertinente debe contribuir a la capacitación de editores, impresores, distribuidores, y libreros locales; a la capacitación de los autores y titulares de derechos locales, así como de los países y comunidades potencialmente beneficiarias de las flexibilidades previstas en el nuevo instrumento.

${ }^{199}$ Véase, e.g.: el artículo 16 del “Acuerdo Comercial Anti-Falsificación” (versión no oficial en español, de 3 de diciembre de 2010). Disponible en http://www.impi. gob.mx/work/sites/IMPI/resources/LocalContent/2361/32/Acuerdo_ACTA_3_ Dic_2010_no_oficial_es.pdf (fecha de consulta: 13 de julio de 2011).

${ }^{200}$ Olian Jr., Irwin A., cit. (n. 10).

${ }^{201}$ El autor tomó parte en el XII Curso Académico Regional OMPI/SGAE Derecho de Autor y Derechos Conexos para Países de América Latina, Santiago de Chile, 9 al 13 de octubre de 2006. 
Sin embargo, la organización internacional competente no debe limitarse a capacitar a terceros, también debe proveer asistencia técnica a los gobiernos a efectos de obtener la implementación de las flexibilidades en su derecho interno, de ser necesario. Ella también debe jugar un rol más proactivo en proveer soporte tecnológico, asistencia financiera, estandarización de buenas prácticas, y análisis crítico acerca del efectivo funcionamiento del sistema.

La organización internacional comptetente deberia ser capaz de adoptar algunas medidas para mejorar el acceso a las obras protegidas por derechos autorales, especialmente por países en desarrollo. Por ejemplo, como se ha mencionado, esta organización podría expedir licencias obligatorias. Esto ayudaría a cumplir la promesa de proveer una amplia diseminación del conocimiento, particularmente en el caso de aquellos países cuyos gobiernos que no desean o son negligentes en expedir dichas licencias, o carecen de capacidades para implementar este mecanismo. Esto también permitiría sortear la fuerte presión que gobiernos extrajeros y titulares de derechos ejercen sobre los países en desarrollo cuanto éstos intentan implementar en su derecho interno algunas de las flexibilidades permitidas por el derecho internacional.

\section{La necesidad de escoger el foro internacional apropiado.}

Responder a la pregunta de cuál es el mejor foro para adoptar un nuevo instrumento internacional que provea flexibilidades para satisfacer necesidades de desarrollo está más allá de un análisis meramente legal, y requiere consideraciones a aspectos políticos, tiempos y agenda de los diferentes foros internacionales potencialmente disponibles. Los siguientes párrafos no proveen una respuesta definitiva, sino sólo una sucinta consideración a algunas de las ventajas y desventajas de los distintos foros.

La primera tentación es considerar la revisión el mismo "Anexo" del "Convenio de Berna", y posiblemente de la Convención universal de derechos de autor, dado que brindan una regulación común para las licencias obligatorias en favor de los países en desarrollo. Sin embargo, la modificación de ellos parece extremadamente compleja, ya que requiere la realización de una conferencia y su aprobación por unanimidad ${ }^{202}$. La Conferencia de París de 1971 requirió una preparación que comenzó con el mismo término de la Conferencia de Estocolmo de 1967. Desde entonces, varias iniciativas para actualizar el "Convenio de Berna" han fracasado, a pesar de disponer del apoyo de los titulares de derechos de autor; de hecho, los países desarrollados han

${ }^{202}$ Véase: BogsCH, Arpad, The First Hundred Years of the Berne Convention for the Protection of Literary and Artistic Works (Ginebra, WIPO, 1986), p. 67, quien sugiere que el propio éxito del "Convenio de Berna" se ha transformado en la causa de su estancamiento, pues su modificación requiere el acuerdo de demasiados países. 
evitado las complicaciones de modificar el "Convenio de Berna" mediante la adopción de nuevos instrumentos en la OMPI y la OMC. Parece ser que el "Convenio de Berna" se ha fosilizado, deviniendo en el testigo del estandar de protección de los derechos autorales en la época industrial, y cualquier mejora debe seguir otra senda.

Otra posibilidad es adoptar un nuevo instrumento internacional específicamente sobre flexibilidades para necesidades de desarrollo en la OMPI. De hecho, actualmente este organismo internacional, el cual forma parte del sistema de Naciones Unidas, trabaja en varias propuestas de instrumentos internacionales en materia de derechos de autor, tales como sobre acceso para personas con discapacidad, sobre excepciones y limitaciones para fines educacionales, sobre protección del conocimiento tradicional, y sobre protección a organismos de radiodifusión, entre otros. De estas propuestas, aquella de un tratado para garantizar acceso a personas con discapacidad a obras protegidas por el derecho de autor es la que más ha avanzado. A pesar de su bien limitado propósito, dicha propuesta ha enfrentado una fuerte oposición de los países desarrollados. Tal experiencia sugiere que un instrumento con propósitos más amplios, tal como proveer flexibilidades para satisfacer necesidades de desarrollo, puede enfrentar una enorme resistencia en tal foro.

Otra alternativa es la OMC. Este organismo internacional es el encargado de hacer cumplir el "Acuerdo sobre los ADPIC" y ya tiene experiencia proveyendo alguna flexibilidad a efectos de permitir acceso a medicinas a los países a través de la emisión de licencias obligatorias, cuando dichos países carecen de capacidades de manufactura, primero a través de un mecanismo temporal ${ }^{203}$, el cual posteriormente se transformó en una modificación al Acuerdo de los ADPIC ${ }^{204}$. Entonces, la OMC a lo menos muestra una exitosa adopción de flexibilidades y algún compromiso con la evaluación de su adopción, implementación, y funcionamiento del Acuerdo sobre los ADPIC y el derecho interno de los países miembros de la OMC. Además, el mencionado acuerdo tiene un mecanismo tutela de que el "Convenio de Berna" carece, y un mayor número de países parte que este último, lo cual provee un más amplia base para la potencial aplicación del nuevo instrumento.

Adoptar un instrumento internacional que provea flexibilidades para satisfacer las necesidades de desarrollo puede tomar bastante tiempo, particularmente si los países desarrollados se oponen a la iniciativa tal como hicieron durante las negociaciones que concluyeron con la adopción del

${ }^{203}$ Decisión del Consejo General de 30 de agosto de 2003, sobre Aplicación del párrafo 6 de la "Declaración de Doha” relativa al "Acuerdo sobre los ADPIC” y la salud pública. WT/L/540 y Corr.1.

${ }^{204}$ Decisión del Consejo General de 6 de diciembre de 2005 sobre Enmienda del “Acuerdo sobre los ADPIC", WT/L/64. 
"Anexo" del "Convenio de Berna". Bajo tales circunstancias, puede ser recomendable trabajar inicialmente en un instrumento más limitado, como un instrumento regional o subregional, como podría ser en el contexto del Mercado Común del Sur ${ }^{205}$ o de la Unión de Naciones Suramericanas ${ }^{206}$. Esto puede crear importantes oportunidades para garantizar un amplio acceso a fuentes del conocimiento con algunas externalidades positivas adicionales, tales como el fortalecimiento de la cultura regional y originaria al promover la preservación de su patrimonio lingüístico. Hoy, un 16\% de las traducciones de obras publicadas en Brasil corresponden a libros originalmente escritos en españo ${ }^{207}$; ese número podría incrementarse bajo un adecuado instrumento. Minorías lingüísticas de países vecinos también podrían disfrutar de los beneficios de economías de escala, tal como hablantes de mapudungun de Argentina y Chile; hablantes de guaraní de Argentina, Brasil, y Paraguay; $y$, hablantes de aymara de Bolivia, Chile, y Perú, entre otros.

Un instrumento regional no parece completamente satisfactorio, pero puede ser un primer paso en el proceso de adopción de un instrumento internacional que provea flexibilidades suficientes para una amplia diseminación del conocimiento a efectos de satisfacer necesidades de desarrollo.

\section{CONCLUSIONES}

El "Anexo" del "Convenio de Berna" intentó proveer algunas flexibilidades para países en desarrollo a efectos de permitirles satisfacer sus necesidades de una amplia diseminación del conocimiento a través de un sistema de licencias obligatorias que ha probado ser ineficiente. Dichos países no han adoptado el burocrático y limitado mecanismo previsto en el Convenio sino que soluciones peculiares en su legislación interna, las cuales varían de un país a otro. Adicionalmente, el "Anexo" suscita incertidumbre jurídica respecto de su aplicación a entornos en línea y resulta insuficiente para satisfacer necesidades de desarrollo, especialmente de minorías culturales y lingüísticas. Estas críticas deberían ser suficientes para instar a la adopción de un nuevo instrumento que provea una solución para satisfacer necesidades de desarrollo. Sin embargo, la adopción de un mecanismo apropiado

${ }^{205}$ Véase el "Tratado de Asunción" del 26 de marzo de 1991, tratado para la constitución de un mercado común entre las Repúblicas Argentina, Federativa de Brasil, del Paraguay y Oriental del Uruguay.

${ }^{206}$ Véase el Tratado constitutivo de la Unión de Naciones Suramericanas, hecho en Brasilia, el 23 de mayo de 2008. Disponible en: http://www.comunidadandina.org/ unasur/tratado_constitutivo.htm (fecha de consulta: 13 de julio de 2011).

${ }^{207}$ Centro Regional para el Fomento del Libro en América Latina, el Caribe, España y Portugal, Cerlalc, cit. (n. 60), p. 84. 
también puede permitir el progreso de cierto bienestar general en relación con la protección de la propiedad intelectual ambicionada por los países desarrollados, e inclusive incrementar las oportunidades para los autores y titulares de derechos.

Una nueva solución para necesidades de desarrollo necesita sacar lecciones de las falencias del "Anexo" del "Convenio de Berna". Necesita extender su ámbito de aplicación, permitir que no sólo los países en desarrollo sino también comunidades puedan ver satisfechas sus necesidades de desarrollo. Necesita diversificar los mecanismos legales disponibles, yendo más allá de un sistema de licencias obligatorias, y reconociendo la variedad de usos y propósitos de dichos usos. Debe reducir y simplificar los trámites, la burocracia, y las medidas de resguardo innecesarias previstas en el sistema actualmente vigente, las que han hecho éste totalmente inoperante. Además, el nuevo instrumento debe sacar ventaja de las oportunidades que ofrecen las tecnologías, no sólo permitiendo claramente su uso para efectos de desarrollo, sino también a efectos de facilitar el funcionamiento del sistema. Finalmente, la organización internacional competente debe jugar un rol más activo fortaleciendo a los países y comunidades que desean sacar partido del sistema de flexibilidades diseñados para ellas, mediante asistencia técnica y capacitación, entre otras responsabilidades.

En sus cuarenta años en vigencia, el "Anexo" del "Convenio de Berna” no ha probado ser eficiente en satisfacer las necesidades de los países en desarrollo; al contrario, se ha probado su persistente fracaso. Si algún balance es requerido urgentemente en la regulación internacional de los derechos de autor es precisamente aquél que permita a los países y comunidades menos desarrollados participar de los progresos de las ciencias, las artes, y la tecnología. Para lograr esto, un nuevo y real compromiso es necesario.

\section{BIBLIOGRAFÍA}

\section{Literatura:}

Abdel Latif, Ahmed, Egypt's Role in the A2K Movement: An Analysis of Positions and Policies, en Rizk, Nagla y Shaver, Lea, Access to Knowledge in Egypt: New Research on Intellectual Property, Innovation and Development (Londres, Bloomsbury Academic, 2010).

AmAdor, Vicente, Intellectual Property Fundamentals (Quezon City - Filipinas, C\&E Publishing, 2007), 781 pp.

Antequera, Ricardo, El nuevo derecho de autor en Venezuela (Caracas, Autoralex, 1994), $821 \mathrm{pp}$.

ANTEQUeRA, Ricardo, Las limitaciones y excepciones al derecho de autor y los derechos conexos en el entorno digital, Document OMPI-SGAE/DA/ASU/05/2, Oct. 26, 2005. 
AQuino, Ranhilio Callangan, Intellectual Property Law: Comments and Annotations (Quezon City, Filipinas, Central Books, 2006), 266 pp.

Armstrong et al, Access to Knowledge in Africa: The Role of Copyright (Sudáfrica, UCT Press, 2010), $366 \mathrm{pp}$.

Austin, Peter y Simpson, Andrew (ed.), Endangered Languages (Hamburgo, Helmut Buske Verlag, 2007), 306 pp.

Awad, Bassem - El-Gheriani, Moatasem - Abou Zeid, Perihan, Egypt, en ArmsTRONG y otros, Access to Knowledge in Africa: The Role of Copyright (Sudáfrica, UCT Press, 2010).

Azam, Mohammad Monirul, Intellectual Property, WTO, and Bangladesh (Dhaka, Bangladesh, New Warsi Book Corp., 2008), 579 pp.

Basalamah, Salah, Compulsory Licensing for Translation: An Instrument of Development?, en IDEA, 40 (2000) 4.

BENET, Josep, Catalunya sota el régim franquista: Informe sobre la persecució de la llengua i la cultura de Catalunya pel régim del general Franco (Barcelona, Blume, 1978), $459 \mathrm{pp}$.

Benet, Josep, L'intent franquista de genocidi cultural contra Catalunya (Barcelona, Publicacions de l'Abadia de Montserrat, 1995), 534 pp.

BogSCH, Arpad, The First Hundred Years of the Berne Convention for the Protection of Literary and Artistic Works (Ginebra, WIPO, 1986).

CÁmARa ChILENA Del Libro, International Standard Book Number, Informe Estadistico 2010 (Santiago de Chile, Cámara Chilena del Libro, 2011), 49 pp.

Castrejon García, Gabino, Tratado Teórico-Práctico de los Derechos de Autor y de la Propiedad Intelectual (Mexico, CCD, 2001).

Centro Regional para el Fomento del Libro en América latina, el CaRibe, España y Portugal-Cerlalc, El Espacio Iberoamericano del Libro 2010 (Santiago de Chile, Cerlalc, 2010), 216 pp.

Chоn, Margaret, Copyright and Capability for Education: an Approach 'From Below', en Wong, Tzen - Dutrield, Graham (editores), Intellectual Property and Human Development: Current Trends and Future Scenarios (Cambridge University Press, 2011).

Chon, Margaret, Intellectual Property "from Below": Copyright and Capability for Education, en University of California Davis Law Review, 40 (2007).

Colombet, Claude, Grandes Principios del Derecho de Autory los Derechos Conexos en el Mundo: Estudio de Derecho Comparado (3a edición, Madrid, UNESCO - CINDOC, 1997).

Consumers International, IP Watch List Report 2009, Thailand Report, disponible en: http://a2knetwork.org/reports2009/thailand (fecha de consulta: 1 de mayo de 2011).

Correa, Carlos, Implications of the Doha Declaration on the Trips Agreement and Public Health, in Health Economics and Drugs Series No 012 (Ginebra, Organización Mundial de la Salud, OMS, 2002) $56 \mathrm{pp}$.

Desbois, Françon, y Kéréver, Les Conventions Internationales du Droit d'Auteur et des Droits Voisins (París, Dalloz, 1976).

Desbois, Henri, La Conférence Diplomatique de Révision des Conventions de Berne et de Genève, en Revue Internationale du Droit d'Auteur, 68 (abril de 1971).

Desurmont, Thierry, Considerations on the Relationship between the Convention on the 
Protection and Promotion of the Diversity of Cultural Expressions and the Protection of Authors'Rights, en Revue Internationale du Droit d'Auteur, 208 (2006).

Drahos, Peter y Braithwaite, John, Information Feudalism: Who Owns the Knowledge Economy? (Londres, Earthscan Publications, 2002), 253 pp.

EL SAGHIR, Hossam A., Intellectual Property Law in Egypt (La Haya, Kluwer International, 2009), $184 \mathrm{pp}$.

Farran, Sue, South Pacific Intellectual Property Law (La Haya, Kluwer International, 2009), 100 pp.

Fernay, Roger, Paris 1971, ou les aventures d'un 'package deal', en Revue Internationale du Droit d'Auteur, 70 (octubre de 1971).

Ficsor, Mihály, Copyright and Transfer of Knowledge, en Copyright Bulletin, 17 (UNESCO, 1983) 3.

FICSOR, Mihály, Limitaciones y Excepciones al Derecho de Autor en el Entorno Digital (Bogotá, Dirección Nacional de Derechos de Autor - CERLALC, 2008).

FICSOR, Mihály, The Law of Copyright and the Internet: the 1996 WIPO Treaties, Their Interpretation, and Implementation (Nueva York, Oxford University Press, 2002), $792 \mathrm{pp}$.

FOMETEU, Joseph, WIPO Study on Limitations and Exceptions for Copyright and Related Rights for Teaching in Africa, Documento OMPI, SCCR/19/5 Oct. 26, 2009.

Goldsmith, Jack y Wu, Tim, Who Controls the Internet: Illusions of a Borderless World (Nueva York, Oxford University Press, 2008), 224 pp.

Hossain, Naznin - AkTaR, Sharifa, Intellectual Property Law (Dhaka, Bangladesh, Mirapura: Phātemā Bukas eṇụa Bhyārāițija, 2009), 751 pp.

Jimenez, Jacinto D., Intellectual Property Law in Philippines (La Haya, Kluwer International, 2007), $178 \mathrm{pp}$.

Karunaratna, D. M., Introduction to the Law of Copyright and Related Rights in Sri Lanka (Sarvodaya Vishva Lekha Publication, 2006), 208 pp.

Kawooya, Dick - Kakungulu, Ronald - Akubu, Jeroline, Uganda, en Armstrong y otros, Access to Knowledge in Africa: The Role of Copyright (Sudáfrica, UCT Press, 2010).

LIPSzyc, Delia, Copyright and Neighbouring Rights (Paris - France, UNESCO Publishing, 1999), $918 \mathrm{pp}$.

Lipszyc, Delia, La Conferencia de Revisión de las Convenciones de Berna y Universal (Paris, Julio de 1971): Enfoque Argentino (Buenos Aires, CISAC, 1975), 139 pp.

Lipszyc - Villalba - UChtenhagen, La protección de los derechos de autor en el sistema interamericano (Bogotá, Universidad Externado de Colombia y Dirección Nacional de Derechos de Autor, 1998), 106 pp.

Merges, Robert P., Contracting into Liability Rules: Intellectual Property Rights and Collective Rights Organizations, en California Law Review, 84 (1996) 5.

Ministerio de Gobierno (de Colombia), Los Derechos de Autor en Colombia (Bogotá, Ministerio de Gobierno, 1982), 178 pp.

Ministerio de Industria, Turismo y Comercio de España, Las traducciones de libros del español al inglés en Reino Unido aumentan un 50\% en tres años, (12/05/2007), disponible en http://www.icex.es/icex/cda/controller/pageICEX /0,6558,5518394_5519005_5604470_4036437,00.html (fecha de consulta: 1 de mayo de 2011).

Mizunami, Pedro y otros, Exceptions and Limitations to Copyright in Brazil: A Call for 
Reform, en Shaver, Lea (editora), Access to Knowledge in Brazil: New Research on Intellectual Property, Innovation and Development (Londres, Bloomsbury, 2010).

Monroy Rodríguez, Juan Carlos, Necesidad de nuevas limitaciones o excepciones para facilitar la digitalización y puesta a disposición de obras protegidas en el marco de la educación virtual, en Revista La Propiedad Inmaterial, 14 (2010).

Monroy Rodríguez, Juan Carlos, WIPO Study on the Limitations and Exceptions to Copyright and Related Rights for the Purpose of Educational and Research Activities in Latin America and the Caribbean, Documento OMPI, SCCR/19/4 Sep. 30, 2004.

Mouchet, Carlos, El derecho de autor internacional en una encrucijada (Buenos Aires, Sociedad de Autores y Compositores de Música, 1969), 138 pp.

NabHan, Victor, WIPO Study on Limitations and Exceptions for Copyright for Educational Purposes in the Arab Countries, Documento OMPI, SCCR/19/6 Oct. 7, 2009.

Ndiaye, Ndéné, The Berne Convention and Developing Countries, en Columbia-VLA Jounal of Law \& the Arts, 11 (1986).

Nordeman - Vinck - Hertin - Meyer, International Copyright and Neighboring Rights Law: Commentary with Special Emphasis on the European Community (Alemania, $\mathrm{VCH}, 1990)$.

Okedij, Ruth L., The International Copyright System: Limitations, Exceptions and Public Interest Considerations for Developing Countries in the Digital Environment (Ginebra, International Centre for Trade and Sustainable Development - ICTSD, 2005), $42 \mathrm{pp}$.

Olian Jr., Irwin A., International Copyrights and the Need of Developing Countries: The Awakening at Stockholm and Paris, en Cornell International Law Journal, 7 (1974) 2.

Paranaguá, Pedro, Excepciones y Limitaciones al Derecho de Autor en Brasil: Logrando un Equilibio entre la Protección y el Acceso al Conocimiento, en CERDA SILVA, Alberto (ed.), Acceso a la Cultura y Derechos de Autor (Santiago de Chile, ONG Derechos Digitales, 2008), pp. 55-77.

Plazas, Arcadio, Estudios sobre Derecho de Autor: Reforma Legal Colombiana (Bogotá - Colombia, Temis, 1984), 305 pp.

Rengifo García, Ernesto, Propiedad intelectual: el moderno derecho de autor (Universidad Externado de Colombia, 1996), 431 pp.

Ricketson, Sam - Ginsburg, Jane C., International Copyright and Neighbouring Rights: The Berne Convention and Beyond (2nd ed., Oxford University Press, 2006), $1540 \mathrm{pp}$.

Ricketson, Sam, The Berne Convention for the Protection of Literary and Artistic Works: 1886-1986 (Londres, Kluwer, 1987), 1030 pp.

RiCKETSON, Sam, WIPO Study on Limitations and Exceptions of Copyright and Related Rights in the Digital Environment, Documento OMPI, SCCR/9/7 April 5, 2003.

Schonwetter, Tobias; Ncube, Caroline; y Chetty, Pria, South Africa, en ArmsTRONG et al, Access to Knowledge in Africa: The Role of Copyright (Sudáfrica, UCT Press, 2010), pp. 231-280.

SENG, Daniel, WIPO Study on the Copyright Exceptions for the Benefit of Educational Activities for Asia and Australia, Documento OMPI, SCCR/19/7, Oct. 29, 2009.

Serrano Migallón, Fernando, Nueva Ley Federal del Derecho de Autor (México, Editorial Porrúa - UNAM, 1998). 
Stewart, S. M., International Copyright and Neighbouring Rights (London, Butterworth, 1983).

Story, Alan, An Alternative Primer on National and International Copyright Law in the Global South: Eighteen Questions and Answers (UK, CopySouth Research Group, 2009), 66 pp.

STORY, Alan, Burn Berne: Why the Leading International Copyright Convention Must Be Repealed, en Houston Law Review, 40 (2003) 3.

Ulmer, Eugen, The Revisions of the Copyright Conventions, en 2 International Review of Intellectual Property and Competition Law, 345 (1971).

UNESCO, Records of the Conference for Revision of the Universal Copyright Convention (Paris, UNESCO, 1973).

Valdés Diaz, Caridad del Carmen, La Facultad de reproducción, en Marta Moreno Cruz y otros, Selección de Lecturas de Derecho de Autor (La Habana, F. Varela, 2000).

World Intellectual Property Organization, Records of the Diplomatic Conference for the Revision of the Berne Convention (Paris, July 5 to 24, 1971) (Ginebra, WIPO, 1974).

World Intellectual Property Organization, Guide to the Berne Convention for the Protection of Literary and Artistic Works (Paris Act, 1971) (Ginebra, WIPO, 1978).

World Intellectual Property Organization, WiPO Intellectual Property Handbook: Policy, Law and Use (Ginebra, WIPO, 2004).

Xue, Hong, Intellectual Property Law in China (Países Bajos, Kluwer International, 2010), 84 pp.

Yu, Peter, TRIPS and Its Discontents, en Marquette Intellectual Property Law Review, 10 (2006).

ZÚNiga, Fernando, Mapudunguwelaymi am? ¿'Acaso ya no hablas Mapudungun?': Acerca del Estado Actual de la Lengua Mapuche, en Estudios Públicos, 105 (2007).

Fuentes Derecho interno:

Copyright Act 1998, consolidated acts of Samoa 2008 (Samoa).

Copyright Act 2005 (Act No 14 of 2005) on May 18, 2005, amending the Copyright Act 2000 (Act No 28 of 2000) (Bangladesh).

Copyright Act of B.E. 2537 (1994) (Thailand)

Copyright Act No 98 of 1978, as amended in 2002 (South Africa).

Copyright and Neighboring Rights Act 19 of 2006 (Uganda).

Copyright and Neighboring Rights Protection Act 1996 (Sudan).

Copyright Law of the People's Republic of China, as amended on Feb. 26, 2010 (República Popular China).

Copyright Protection Act $\mathrm{N}^{\circ}$ (22) of 1992, as amended by the Amending Law $\mathrm{N}^{\circ}$ (9) of 2005 (Jordania).

Decree of the State Council of the People's Republic of China No 468: Regulations on Protection of the Right of Communication through Information Network, adopted at the 135 Executive Meeting of the State Council on May 10, 2006 (República Popular China).

Decreto No 604 de 1993 Ley de fomento y protección de la propiedad intelectual (El Salvador). 
Decreto No 4-99-E, 2000, Ley del derecho de autor y de los derechos conexo, texto consolidado 2006 (Honduras).

Decreto No 362-01 del 14 de marzo del 2001 que establece el reglamento de aplicación de la Ley N ${ }^{\circ}$ 65-00 Sobre derecho de autor (República Dominicana).

Dirección Nacional de Derecho de Autor, Colombia, Concepto 1-2010-7340, 21 de mayo de 2010.

Federal Law No (7) of the Year 2002 Concerning Copyrights and Neighboring Rights (Emiratos Árabes Unidos).

Intellectual Property Code of the Philippines (Republic Act No 8293) of June 6, 1997 (Filipinas).

Intellectual Property Act, № 36 of 2003 (Sri Lanka).

Intellectual Property Rights Law No 19 of 1994 (Yemen).

Law No 12/2001 Copyright Law of Syria (Siria).

Law No 64 of 1999 concerning Intellectual Property Rights, December 29, 1999 (Kuwait).

Law of Mongolia on Copyright and Related Rights, January 19, 2006 (Mongolia).

Law of the Republic of Uzbekistan on Copyright and Related Rights 2006 (Uzbekistan).

Law on Intellectual Property No 50/2005/QH11 of November 29, 2005 (Vietnam).

Law on the Protection of Intellectual Property Rights 82 of 2002, Official Gazette, June 2, 2002 (Egipto).

Ley No 14 del Derecho de autor de 1977 (Cuba).

Ley No 15 (De 8 de agosto de 1994) Ley sobre el derecho de autor y derechos conexos (Panamá).

Ley No 23 de 1982 Sobre derechos de autor, Diario Oficial, Febrero 19, 1982 (Colombia)

Ley No 65-00 de Derechos de autor, Gaceta Oficial, Agosto 24, 2000 (República Dominicana).

Ley No 1322 de 1992: Ley de derechos de autor, Gaceta Oficial, Abril 27, 1992 (Bolivia).

Ley No 17.336 Sobrepropiedad intelectual [Intellectual Property Act], as amended, Diario Oficial, Mayo 4, 2010 (Chile)

Ley federal del derecho de autor, Diario Oficial de la Federación, Dic. 24, 1996, texto consolidado Julio 2003 (México).

Prime Minister Decree No 497 of 2005 On Issuing the Executive Regulations for Book III Of Law No (82) of 2002 on The Protection of Intellectual Property Rights (Egipto).

Reglamento de la ley federal del derecho de autor, Diario Oficial de la Federación, Mayo 22, 1998, modificado el Septiembre 14, 2005 (México).

Royal Decree No 65/2008 Promulgating the Law on Copyright and Related Rights (Oman).

Fuentes derecho internacional:

Acuerdo Comercial Anti-Falsificación (versión no oficial en español, de 3 de diciembre de 2010). Disponible en http://www.impi.gob.mx/work/sites/IMPI/resources/ LocalContent/2361/32/Acuerdo_ACTA_3_Dic_2010_no_oficial_es.pdf(fecha de consulta: 13 de julio de 2011).

"Acuerdo de Cartagena", Bogotá, de 28 de mayo de 1969.

Acuerdo sobre los aspectos de los derechos de propiedad intelectual relacionados con el comercio (ADPIC), 15 de abril de 1994. 
Acuerdo de Marrakesh que Establece la Organización Mundial de Comercio, "Anexo" 1C, 1869 U.N.T.S. 299

Convención interamericana sobre el derecho de autor en obras literarias, cientificas y artísticas, adoptada en Washington D.C., el 22 de junio de 1946.

Convención sobre la protección y promoción de la diversidad de las expresiones culturales, UNESCO, París, 20 de octubre 2005.

Convención universal sobre derecho de autor, Ginebra, 6 de septiembre de 1952.

"Convenio de Berna" para la Protección de las Obras Literarias y Artísticas, Acta de París del 24 julio de 1971 y enmendado el 28 de septiembre de 1979.

Convención sobre el derecho de los tratados, suscrita en Viena el 23 de mayo de 1969, U.N. Doc A/CONF.39/27 (1969), 1155 U.N.T.S. 331.

Decisión No 351 Régimen común sobre derecho de autor y derechos conexos, adoptada por la Comisión del Acuerdo de Cartagena, el 17 de diciembre de 1993, Gaceta Oficial de la Comunidad Andina No 145, 21 de diciembre de 1993.

Decisión del Consejo General de 30 de agosto de 2003, sobre Aplicación del párrafo 6 de la Declaración de Doha relativa al acuerdo sobre los ADPIC y la salud pública. WT/L/540 y Corr.1.

Decisión del Consejo General de 6 de diciembre de 2005 sobre Enmienda del Acuerdo sobre los ADPIC. WT/L/64.

Directiva 2004/48/CE del Parlamento Europeo y del Consejo de 29 de abril de 2004 relativa al respeto de los derechos de propiedad intelectual, Diario Oficial de la Unión Europea No L 195 de 02/06/2004, pp. 0016 - 0025.

Propuesta del Brasil, el Ecuador y el Paraguay en relación la limitaciones y excepciones: Propuesta de tratado de la Unión Mundial de Ciegos (UMC), Documento OMPI, SCCR/18/5, 25 de mayo de 2009. Disponible en www.wipo.int/edocs/mdocs/ copyright/es/sccr_18/sccr_18_5.doc (fecha de consulta: 13 de julio de 2011).

Proyecto de tratado de la OMPI sobre excepciones y limitaciones para las personas con discapacidad, las instituciones docentes y de investigación, las bibliotecas y los archivos, Propuesta del Grupo Africano, Documento OMPI, SCCR/20/11, 15 de junio de 2010. Disponible en www.wipo.int/edocs/mdocs/copyright/es/sccr_20/ sccr_20_11.doc (fecha de consulta: 13 de julio de 2011).

Trans-Pacific Partnership - Intellectual Property Rights Chapter: Draft - Feb. 10, 2011 (versión no oficial). Disponible en: http://keionline.org/sites/default/files/tpp-10feb2011-us- text-ipr-chapter.pdf (fecha de consulta: 13 de julio de 2011).

Tratado constitutivo de la Unión de Naciones Suramericanas, hecho en Brasilia - Brasil, el 23 de mayo de 2008.

“Tratado de Asunción” del 26 de marzo de 1991.

Tratado sobre propiedad literaria y artística, firmado en Montevideo el 11 de enero de 1889. 